\title{
Early growth response gene 1 (Egr-1) is required for new and reactivated fear memories in the lateral amygdala
}

\author{
Stephanie A. Maddox, ${ }^{1}$ Melissa S. Monsey, ${ }^{1}$ and Glenn E. Schafe ${ }^{1,2,3}$ \\ ${ }^{1}$ Department of Psychology, Yale University, New Haven, Connecticut 06520, USA; ${ }^{2}$ Interdepartmental Neuroscience Program, \\ Yale University, New Haven, Connecticut 06520, USA
}

\begin{abstract}
The immediate-early gene early growth response gene-1 (EGR-1, zif-268) has been extensively studied in synaptic plasticity and memory formation in a variety of memory systems. However, a convincing role for EGR-1 in amygdala-dependent memory consolidation processes has yet to emerge. In the present study, we have examined the role of EGR-1 in the consolidation and reconsolidation of amygdala-dependent auditory Pavlovian fear conditioning. In our first series of experiments, we show that EGR-1 is regulated following auditory fear conditioning in the lateral nucleus of the amygdala (LA). Next, we use antisense oligodeoxynucleotide (ODN) knockdown of EGR-1 in the LA to show that training-induced expression of EGR-1 is required for memory consolidation of auditory fear conditioning; that is, long-term memory (LTM) is significantly impaired while acquisition and short-term memory (STM) are intact. In a second set of experiments, we show that EGR-1 is regulated in the LA by retrieval of an auditory fear memory. We then show that retrieval-induced expression of EGR-1 in the LA is required for memory reconsolidation of auditory fear conditioning; that is, post-retrieval (PR)-LTM is significantly impaired while memory retrieval and PR-STM are intact. Additional experiments show these effects to be restricted to the LA, to be temporally graded, and unlikely to be due to nonspecific toxicity within the LA. Collectively, our findings strongly implicate a role for EGR-1 in both the initial consolidation and in the reconsolidation of auditory fear memories in the LA.
\end{abstract}

A considerable amount of progress has been made in identifying the cellular and molecular mechanisms underlying the acquisition and consolidation of Pavlovian fear conditioning (Schafe et al. 2001; Rodrigues et al. 2004). More recently, interest has also grown in the question of whether these same cellular processes may underlie fear memory "reconsolidation," the process whereby fear memories are restabilized at synapses within the lateral nucleus of the amygdala (LA) after retrieval (Nader et al. 2000; Tronson and Taylor 2007). Collectively, findings have suggested that both consolidation and reconsolidation involve $\mathrm{N}$-methyl-D-aspartate receptor (NMDAR)-driven alterations in synaptic transmission within the LA (Rodrigues et al. 2001; Ben Mamou et al. 2006) and the resultant activation of protein kinase signaling pathways (Schafe and LeDoux 2000; Schafe et al. 2000; Moita et al. 2002; Duvarci et al. 2005; Tronson et al. 2006) and transcription factors (Hall et al. 2001a; Josselyn et al. 2001) in LA neurons.

While both fear memory consolidation and reconsolidation are known to require de novo mRNA and protein synthesis in the LA (Bailey et al. 1999; Nader et al. 2000; Schafe and LeDoux 2000; Duvarci et al. 2008), relatively little remains known about the downstream genes that underlie these processes. One widely studied candidate gene is the early growth response gene- 1 (EGR-1; also known as zif-268, NGFI-1, Krox-24), a member of a family of zinc finger inducible transcription factors that is believed to be critical for regulating the transcription of late-response genes that promote functional and/or structural changes underlying long-term synaptic plasticity and memory formation (Davis et al. 2003; Knapska and Kaczmarek 2004). In other memory systems, EGR-1 has been implicated in long-term

\footnotetext{
${ }^{3}$ Corresponding author.
}

E-mail glenn.schafe@yale.edu; fax (203) 432-7172.

Article is online at http://www.learnmem.org/cgi/doi/10.1101/lm.1980211. forms of experience-dependent synaptic plasticity (Cole et al. 1989; Richardson et al. 1992; Abraham et al. 1993; Bramham et al. 1996; Davis et al. 2000; Jones et al. 2001; Håvik et al. 2003; Renaudineau et al. 2009) and in memory formation, including song learning in songbirds, in vitro eye-blink conditioning in turtles, and in object recognition memory and spatial learning in rats (Mello and Clayton 1994; Jones et al. 2001; Bozon et al. 2003a; Mokin and Keifer 2005; Soulé et al. 2008). Recent studies have also implicated EGR-1 in memory reconsolidation processes, including those associated with contextual fear conditioning in the hippocampus (Lee et al. 2004; Lee 2008) and cue-induced drug seeking in the amygdala (Lee et al. 2006). Studies examining the role of EGR-1 in fear memory consolidation and reconsolidation in the amygdala, however, have yielded largely contradictory results. One study, for example, reported significant trainingrelated regulation of EGR-1 mRNA in the LA following acquisition, but not retrieval, of a contextual fear conditioning task (Malkani and Rosen 2000), suggesting that EGR-1 plays a critical role in consolidation but not reconsolidation of fear memories. Conversely, other studies have reported significant regulation of EGR-1 mRNA in the LA following retrieval of a contextual fear memory (Hall et al. 2001b), but have failed to find trainingspecific changes after contextual fear learning (Hall et al. 2000), suggesting that EGR-1 is critical for reconsolidation but not consolidation processes in the LA.

In the present study, we have re-examined the role of EGR-1 in the consolidation and reconsolidation of Pavlovian fear memories in the LA using an auditory fear conditioning task. We first examine the regulation of EGR-1 protein within the LA and surrounding nuclei of the amygdala following either auditory fear conditioning or retrieval of an auditory fear memory. Next, we use local infusions of an EGR-1 antisense oligodeoxynucleotide (ODN) to examine the role of EGR-1 in auditory fear memory consolidation and reconsolidation in the LA. 


\section{Results}

EGR-1 is significantly up-regulated in the LA following auditory fear conditioning and is required for fear memory consolidation

While EGR-1 has been extensively studied in synaptic plasticity and memory formation in a variety of memory systems (Mello and Clayton 1994; Bozon et al. 2003a; Mokin and Keifer 2005), studies examining the role of EGR-1 in amygdala-dependent memory consolidation processes have produced conflicting findings (Hall et al. 2000, 2001b; Malkani and Rosen 2000). Malkani and Rosen (2000), for example, reported significant regulation of EGR-1 mRNA in the LA following contextual fear conditioning (Malkani and Rosen 2000). However, Hall and colleagues found equivalent increases in EGR-1 mRNA expression in the LA following exposure to the context alone, suggesting that EGR-1 may not play a selective role in fear learning (Hall et al. 2000). This latter pattern of findings is consistent with a recent study that has shown that exposure to a novel context alone can induce robust expression of a variety of genes in the LA (Ploski et al. 2010), and suggests that the use of contextual fear conditioning paradigms may be potentially problematic for the study of gene expression following fear learning (Davis et al. 2003). In the present series of experiments, we have re-examined the role of EGR-1 in the consolidation of fear memories in the LA using an auditory fear conditioning task. Unlike contextual fear learning tasks, auditory fear conditioning paradigms provide a means to examine training-related changes in gene expression in the absence of those driven by exposure to a novel context (Ploski et al. 2010). In our first series of experiments, we asked whether auditory fear conditioning regulates the expression of EGR-1 protein in the LA. We then asked whether EGR-1 expression in the LA is obligatory for auditory fear memory formation and/or consolidation.

\section{Auditory fear conditioning regulates EGR-1 expression in the $L A$}

Using immunohistochemistry, we first examined if EGR-1 expression in the LA following auditory fear conditioning is specific to memory formation. In the first experiment, we examined EGR-1 expression in rats receiving paired presentations of tone and shock ("Paired") relative to those receiving immediate shock ("Imm. Shock") or no stimulation ("Naïve"). In a second experiment, we examined EGR-1 expression in Paired rats relative to those receiving tone alone ("Tone Alone") or no stimulation ("Naïve"). To rule out the possibility that exposure to the conditioning chamber alone might induce EGR-1 in the LA, rats in this second experiment received extensive habituation to both handling and to the conditioning chamber for $4 \mathrm{~d}$ prior to fear conditioning, a procedure that we have previously shown to be useful in significantly reducing novelty-induced gene expression in the LA (Ploski et al. 2010). In each of our experiments, EGR-1 labeling was found throughout the dorsal tip of the LA (LAd), ventral portion of the LA (LAv), basal (B), and the central nucleus of the amygdala (CE) (Fig. 1A). In both experiments, the most prominent labeling was observed in the LAd, a set of findings similar to those observed previously at the mRNA level (Malkani and Rosen 2000).

The first experiment revealed a high level of EGR-1 labeled cells in the paired group relative to both immediate shock and naïve groups (Fig. 1B). Representative photomicrographs for paired, immediate shock, and naïve rats are displayed in Figure 1C-E, and higher magnification photomicrographs of a representative paired rat are displayed in Figure 1F, G. Specifically, a main effect of group was observed in the $\operatorname{LAd}\left(F_{(2,6)}=35.66\right.$,
$P<0.01)$, the $\operatorname{LAv}\left(F_{(2,6)}=19.38, P<0.01\right)$, the B $\left(F_{(2,6)}=67.52\right.$, $P<0.01)$, and the CE $\left(F_{(2,6)}=13.04, P<0.01\right)$. Duncan's post-hoc tests revealed significantly more EGR-1 labeled cells in the paired group within the LAd, LAv, B, and CE $(P<0.01)$ compared to both the immediate shock and naïve groups, while the immediate shock group displayed significantly more EGR-1 labeled cells in the LAd, LAv, B, and CE relative to the naïve group $(P<0.01)$.

The second experiment demonstrated a high level of EGR-1 labeled cells in the paired group relative to both the tone alone and naive groups (Fig. 1H). Specifically, a main effect of group was observed in the LAd $\left(F_{(2,15)}=6.21, P<0.01\right)$, the LAv $\left(F_{(2,15)}=7.82, P<0.01\right)$, the B $\left(F_{(2,15)}=10.74, P<0.01\right)$, and the CE $\left(F_{(2,15)}=5.41, P<0.02\right)$. Duncan's post-hoc tests revealed significantly more EGR-1 labeled cells in the paired group within the LAd, LAv, B, and CE $(P<0.01)$, while no significant differences were observed in EGR-1 labeled cells between naïve and tonealone groups in any of the amygdala subnuclei $(P>0.05)$.

Thus, auditory fear conditioning promotes significant regulation of EGR-1 protein in several amygdala subnuclei (LAd, $\mathrm{LAv}, \mathrm{B}, \mathrm{CE})$. Further, this effect is most prominent in rats receiving paired presentations of tone and shock, and cannot be accounted for by exposure to a novel context, novel tone, or to shock alone.

\section{EGR-1 antisense results in significant knockdown of EGR-1 protein in the LA}

Our initial series of experiments showed that EGR-1 protein is regulated in the LA by auditory fear conditioning. In our next series of experiments, we asked whether EGR-1 is obligatory for fear memory consolidation using localized antisense ODN knockdown of EGR-1 protein in the LA. In our first experiment, we verified the efficacy of EGR-1 antisense ODN in reducing EGR-1 protein levels in the LA following auditory fear conditioning. Rats received an intra-LA infusion of the EGR-1 antisense ODN ( $250 \mathrm{pmol} ; 1 \mu \mathrm{L}$ ) on one side of the brain and an equivalent dose and volume of scrambled ODN on the contralateral side of the brain $90 \mathrm{~min}$ prior to auditory fear conditioning. Rats were then sacrificed $2 \mathrm{~h}$ later and punches were taken from the LA and homogenized. Western blot analysis revealed a significant knockdown of EGR-1 protein on the antisense-infused side of the brain compared to the scrambled-infused side $\left(t_{(20)}=3.34\right.$, $P<0.01$; Fig. 2A). No significant difference was observed between the levels of the loading control GAPDH $\left(t_{(20)}=0.58, P>0.05\right)$ (data not shown).

\section{EGR-1 antisense is restricted to the $L A$}

Next, we determined the duration and extent of diffusion of the EGR-1 antisense ODN following infusion into the LA. A biotinylated EGR-1 antisense ODN ( 250 pmol; $1 \mu \mathrm{L}$ ) was infused bilaterally into the LA and rats were sacrificed 30,60 , or $180 \mathrm{~min}$ following infusions. Figure $2 \mathrm{~B}-\mathrm{D}$ shows the diffusion of the biotinylated ODN in the LA 30 min following infusion. Diffusion of the ODN was largely restricted to the LA, sparing the B and CE nuclei and surrounding cortical areas. At higher levels of magnification (Fig. 2C,D), the ODN was observed to be localized to cells within the LA, which suggests that the ODN was actively taken up by cells. The expression of biotinylated EGR-1 ODN was less pronounced 60 and $180 \mathrm{~min}$ after infusion (images not shown).

\section{EGR-1 knockdown in the LA impairs fear memory consolidation}

Our initial findings showed that EGR-1 protein is significantly up-regulated in the LA following auditory fear memory conditioning (Fig. 1) and that intra-LA infusion of an EGR-1 antisense ODN impairs training-induced EGR-1 expression in the LA in an anatomically restricted manner. In this next series of experiments, we examined the effect of EGR-1 knockdown in the LA on 
A
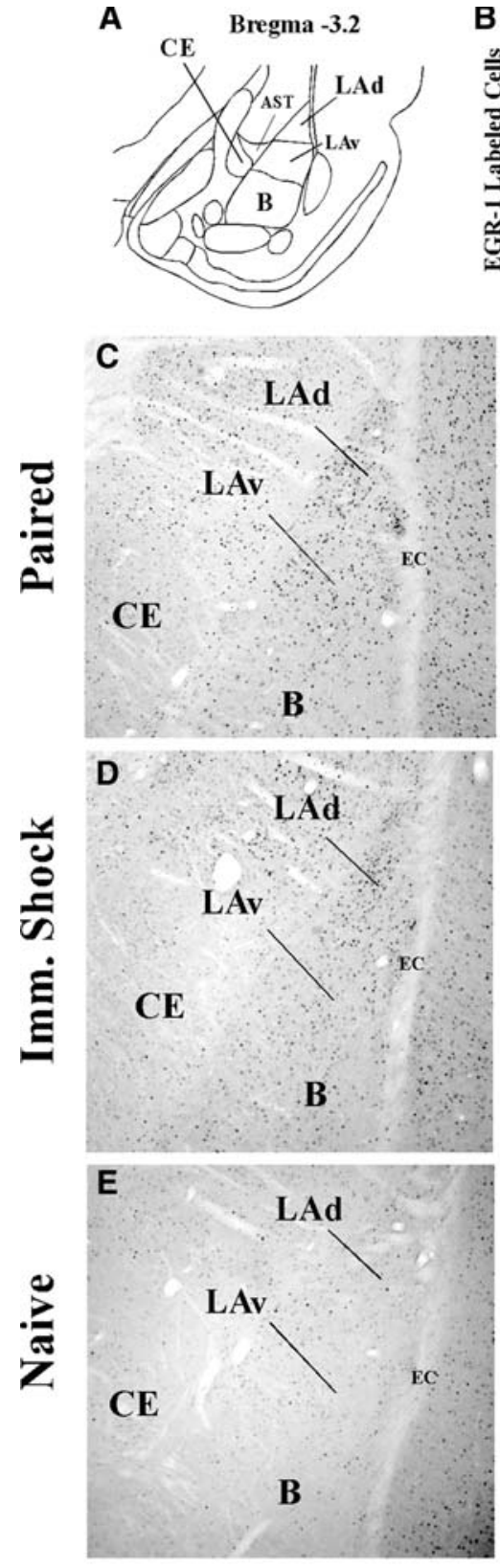
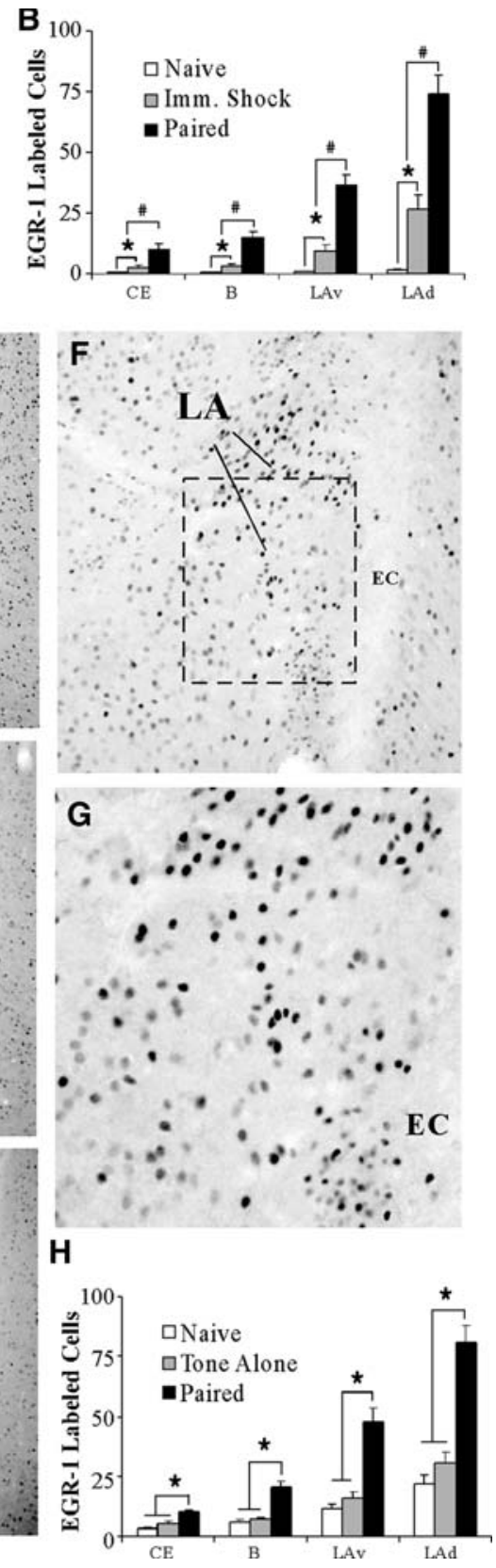

Figure 1. Fear conditioning regulates EGR-1 protein expression in the amygdala. ( $A$ ) A representative diagram of the amygdala at $\sim$ bregma -3.2 showing the location of the dorsal tip of the lateral nucleus (LAd), the ventral portion of the LA (LAv), the basal nucleus (B), and the central nucleus of the amygdala (CE). The amygdala-striatal transition zone (AST) is also depicted. (B) Quantification of EGR-1 labeled cells in the CE, B, LAv, and LAd of naïve $(n=3), \operatorname{lmm}$. Shock $(n=3)$ and Paired $(n=3)$ groups following fear conditioning. ${ }^{\#} P<0.05$ relative to $1 \mathrm{~mm}$. Shock group. ${ }^{*} P<0.05$ relative to naive group. (C-E) Representative 10X photomicrographs of immunolabeled EGR-1 cells in a Paired, Imm. Shock, and Naive rats, respectively. $(F, G)$ Higher level (20X and 40X, respectively) magnifications of EGR-1 labeled cells from the Paired rat. $(H)$ Quantification of EGR-1 labeled cells in the CE, B, LAv, and LAd of naïve $(n=5)$, Tone Alone $(n=7)$, and Paired $(n=6)$ groups following fear conditioning. ${ }^{*} P<$ 0.05 relative to naïve and tone alone groups.

auditory fear memory consolidation. A schematic of the behavioral paradigm is depicted in Figure 3A. Rats were infused with either EGR-1 scrambled or antisense ODNs ( $250 \mathrm{pmol} ; 1 \mu \mathrm{L})$ and trained 90 min later (Fig. 3B). There was no difference in the levels of postshock freezing between the scrambled and antisense groups. An analysis of variance (ANOVA) revealed no significant main effect

of group $\left(F_{(1,13)}=0.00, P>0.05\right)$ or group by trial interaction $\left(F_{(2,13)}=0.00, P>\right.$ $0.05)$; however, there was a significant main effect of trial $\left(F_{(1,13)}=80.29, P<\right.$ $0.01)$, indicating that there was an increase in post-shock freezing relative to the pre-CS period. In addition, both groups showed equivalent STM when tested for auditory fear memory in a different chamber $3 \mathrm{~h}$ after training (Fig. 3C). The ANOVA (group by trial) revealed no significant effects of group $\left(F_{(1,13)}=\right.$ $0.93, P>0.05)$, trial $\left(F_{(2,26)}=2.08, P>\right.$ $0.05)$, or the group by trial interaction $\left(F_{(2,26)}=0.27, P>0.05\right)$. Thus, knockdown of EGR-1 protein in the LA does not interfere with the acquisition or STM formation of auditory fear memories.

In contrast to the demonstration of intact acquisition and STM, the group infused with EGR-1 antisense ODN exhibited significantly impaired LTM, as examined by a test $24 \mathrm{~h}$ after training (Fig. 3D). The ANOVA (group by trial) revealed significant main effects of group $\left(F_{(1,13)}=43.58, P<0.01\right)$ and trial $\left(F_{(9,117)}=8.46, P<0.01\right)$, as well as a significant group by trial interaction $\left(F_{(9,117)}=3.81, P<0.01\right)$. Duncan's posthoc $t$-tests revealed that freezing scores of the EGR-1 antisense group were significantly different from the scrambled ODN group on trials 1-9 of the LTM test $(P<0.05)$. As another measure of the consolidation deficit observed in the EGR-1 antisense ODN group, we next expressed each rat's freezing score during the LTM test as a percentage of that during the STM test (Fig. 3E). Analysis revealed that the EGR-1 antisense ODN group displayed significantly less retention during the LTM test than the scrambled ODN group $\left(t_{(13)}=11.26\right.$, $P<0.01)$. Thus, knockdown of EGR-1 via antisense ODN infusions in the LA significantly impairs LTM formation, while leaving acquisition and STM intact. Cannula placements are shown in Figure $3 \mathrm{H}$.

\section{EGR-1 antisense knockdown in the LA does not result in nonspecific damage to the $L A$}

To exclude the possibility that local EGR-1 antisense ODN infusions resulted in damage to the LA that emerges over the course of $24 \mathrm{~h}$ (e.g., between the time of the STM and LTM tests), rats infused with EGR-1 antisense in the initial experiment were retrained approximately $1 \mathrm{wk}$ later without ODN infusion and then retested for LTM on the following day (Fig. 3F). During the LTM retest, the antisense-infused rats showed levels of freezing equivalent to those exhibited by the scrambled group in the initial experiment (Fig. 3F). An ANOVA comparing the freezing scores of the scrambled group during the initial LTM test and that of the 

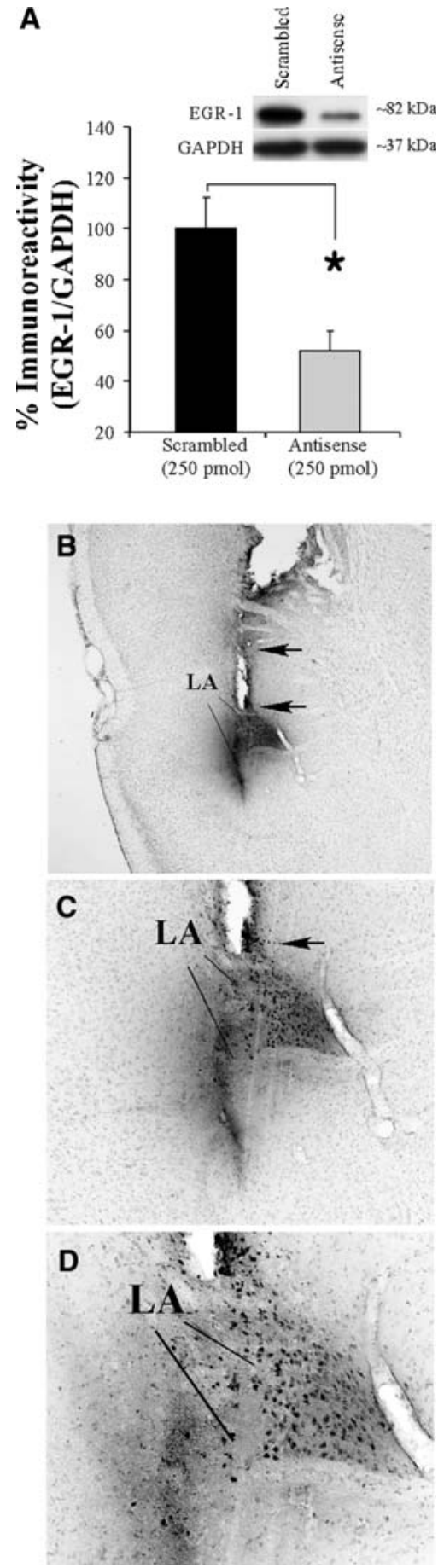

Figure 2. Antisense ODN knockdown of EGR-1 protein in the LA. (A) Western blot analysis of EGR-1 protein from LA homogenates from rats given intra-LA infusion of antisense and scrambled ODNs (250 pmol; $1 \mu \mathrm{L}$ ) on opposite sides of the brain, trained, and sacrificed $2 \mathrm{~h}$ later $(n=12)$. Here, EGR-1 is expressed relative to the loading control GAPDH for each sample, and the values for the antisense ODN-infused side are expressed relative to that of the scrambled ODN-infused side. ${ }^{*} P<0.02$ relative to the scrambled ODN-infused side. (B) Representative $4 \mathrm{X}$ photomicrograph of a rat infused with biotinylated EGR-1 ODN (250 pmol; $1 \mu \mathrm{L})$ and sacrificed 30 min later. Note that the diffusion of the ODN is largely restricted to the LA and spares the basal and central nuclei of the amygdala. $(C, D)$ Higher level (10X and 20X, respectively) magnifications of LA neurons containing biotinylated EGR-1 ODN. Note the large number of LA cells expressing the biotin label. antisense group during the LTM retest revealed no significant main effect of group $\left(F_{(1,13)}=0.17, P>0.05\right)$ or group by trial interaction $\left(F_{(9,117)}=0.81, P>0.05\right)$, yet did reveal a significant main effect of trial $\left(F_{(9,117)}=6.33, P<0.05\right)$. These findings demonstrate that antisense-infused rats are able to reacquire a fear association at levels comparable to those of scrambled-infused controls, and suggest that EGR-1 antisense infusion does not result in damage to the LA, which may prevent fear expression during the initial 24-h LTM test.

\section{The effect of EGR-1 knockdown on consolidation of auditory fear memory is specific to the $L A$}

It is possible that the consolidation deficit observed in the EGR-1 antisense group could be attributed to ODN diffusion outside of the LA. To address this issue, we next examined the performance of rats with misplaced cannulas (Fig. 3G). Misplaced rats were defined as those rats with cannula tips located outside of the LA, and included rats with unilateral LA infusions (i.e., one side in the LA and the other side outside of the LA), as well as rats with bilateral placements outside of LA. Placements are shown in Figure 3I. In most cases, bilateral misplaced cannulas were found to be in the cortex adjacent to the LA. An ANOVA comparing percent freezing during the LTM test of the well-placed scrambled and antisense groups vs. the misplaced scrambled and antisense groups revealed a significant main effect of group $\left(F_{(3,22)}=\right.$ 21.60, $P<0.01)$, trial $\left(F_{(9,198)}=17.77, P<0.01\right)$, and group by trial interaction $\left(F_{(27,198)}=2.13, P<0.01\right.$; Fig. 3G). Duncan's post-hoc tests revealed that the well-placed antisense group was significantly different from all other groups on trials $1-9(P<$ 0.05). In contrast, freezing scores of the well-placed scrambled, misplaced scrambled, and misplaced antisense groups were not significantly different on any of the trials, with the exception of trial 4 where the misplaced antisense group was significantly different from the LA-placed scrambled group $(P<0.05)$. Thus, the deficit in auditory fear memory consolidation observed in the EGR-1 antisense group cannot be attributed to ODN diffusion into the areas surrounding the LA.

\section{The effect of EGR-1 knockdown in the LA on auditory fear memory consolidation is time-limited}

Next, we examined whether the effects of EGR-1 knockdown in the LA on fear memory consolidation are time-limited. Previous studies have suggested that fear memories in the LA are insensitive to protein synthesis inhibition $6 \mathrm{~h}$ following training (Schafe and LeDoux 2000), suggesting that the "consolidation window" is closed by that time. In the present experiment, rats were trained and given intra-LA infusions of either EGR-1 scrambled or antisense ODN $6 \mathrm{~h}$ later followed by a LTM test $24 \mathrm{~h}$ later (Fig. 4A). There was no significant difference between the scrambled and antisense groups in the level of post-shock freezing following CS-US pairing (Fig. 4B). An ANOVA revealed only a significant main effect of trial $\left(F_{(1,9)}=349.19, P<0.01\right)$; there was no significant main effect of group $\left(F_{(1,9)}=2.24, P>0.05\right)$ or group by trial interaction $\left(F_{(1,9)}=2.24, P>0.05\right)$. Furthermore, no significant group difference in freezing levels was observed during the LTM test $24 \mathrm{~h}$ after infusions $\left(F_{(1,9)}=1.29, P>0.05\right.$; Fig. $\left.4 \mathrm{C}\right)$ and there was no group by trial interaction $\left(F_{(9,81)}=0.84, P>0.05\right)$. Thus, these findings are consistent with the time-limited role of memory consolidation processes (Davis and Squire 1984), which likely occur within $6 \mathrm{~h}$ of training. Cannula placements are shown in Figure $4 \mathrm{G}$.

EGR-1 antisense infusions in the LA do not result in hyperactivity 24 h later Another possible explanation for the disruption of auditory fear memory consolidation via EGR-1 knockdown in the LA is that 


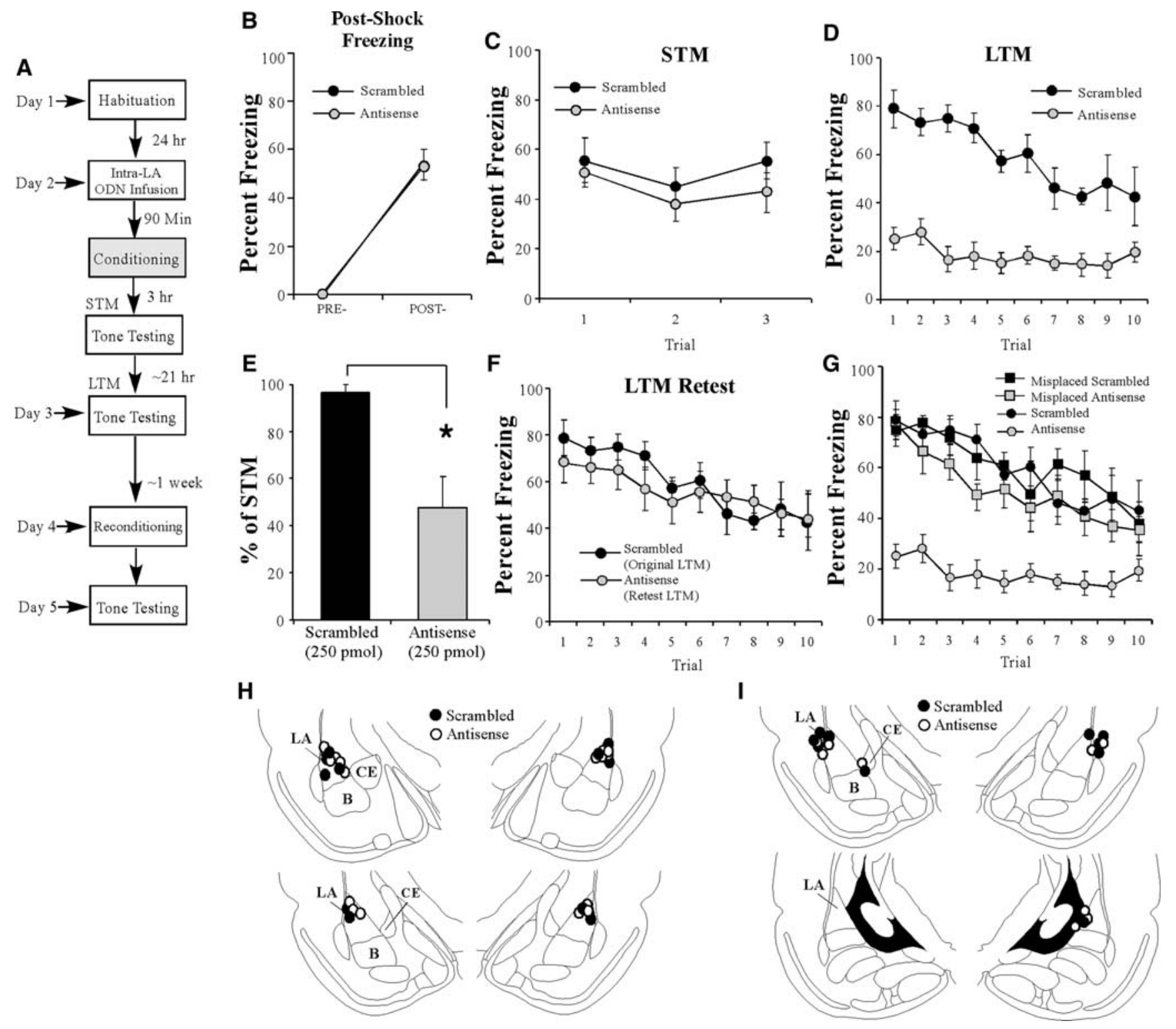

Figure 3. Antisense knockdown of EGR-1 protein in the LA impairs auditory fear memory consolidation. (A) Schematic of the behavioral protocol. Rats were given intra-LA infusion of either EGR-1 antisense $(n=9)$ or scrambled $(n=6)$ ODN $(250 \mathrm{pmol} ; 1 \mu \mathrm{L} / \mathrm{side}) 90$ min before fear conditioning. STM was examined in a distinct context $3 \mathrm{~h}$ later and LTM was examined $24 \mathrm{~h}$ after the conclusion of training. (B) Post-shock freezing in each group immediately after the conditioning trial. (C) Auditory fear memory assessed at $3 \mathrm{~h}$ after fear conditioning for each group across all three tone presentations. (D) Auditory fear memory assessed $24 \mathrm{~h}$ after fear conditioning for each group across all 10 tone presentations. (E) LTM depicted as a percentage of STM for each rat in each group. ${ }^{*} P<0.01$ relative to the scrambled group. $(F)$ Antisense-infused rats were retrained in the absence of ODN infusion 1 wk later and retested $24 \mathrm{~h}$ later. Here, freezing scores for the retrained antisense rats are depicted together with those of the scrambled rats used in the initial LTM test. (G) Auditory fear memory assessed $24 \mathrm{~h}$ after fear conditioning across all 10 tone presentations for misplaced antisense ( $n=6$; gray squares) and scrambled $(n=5 ; \square)$ groups. Here, misplaced rats in each group are depicted together with the well-placed antisense (gray circles) and scrambled groups $(\bullet)$ from the initial LTM test. $(H)$ Histological verification of intra-LA (well-placed) cannula placements for rats infused with either antisense $(O)$ and or scrambled $(\bullet)$ ODNs. (I) Histological verification of cannula placement for misplaced rats. Panels adapted from Paxinos and Watson (1998) and reprinted with permission from Elsevier (C) 1998.

the antisense infusion resulted in some nonspecific effect on general activity levels $24 \mathrm{~h}$ after the infusion, rendering rats hyperactive and thus unable to freeze during LTM testing. To address this possibility, we infused a separate group of rats with either EGR-1 scrambled or antisense ODN in the LA. Approximately $24 \mathrm{~h}$ later, rats were trained with a single tone-shock pairing and then given a STM test $3 \mathrm{~h}$ later, at approximately the same time as rats were tested for LTM in the previous experiments (Fig. 4D). There was no significant difference between the scrambled and antisense groups in post-shock freezing levels (Fig. 4E). An ANOVA revealed a significant main effect of trial $\left(F_{(1,6)}=123.99, P<0.01\right)$, but no significant main effect of group $\left(F_{(1,6)}=0.02, P>0.05\right)$ or the group by trial interaction $\left(F_{(1,6)}=0.02, P>0.05\right)$. In addition, there was no difference in freezing levels $3 \mathrm{~h}$ later during STM testing (Fig. 4F). The ANOVA (group by trial) revealed a nonsignificant main effect of group $\left(F_{(1,6)}=0.42, P>0.05\right)$ and a nonsignificant group by trial interaction $\left(F_{(2,12)}=1.66, P>\right.$ $0.05)$. Therefore, it is unlikely that the freezing deficits observed 

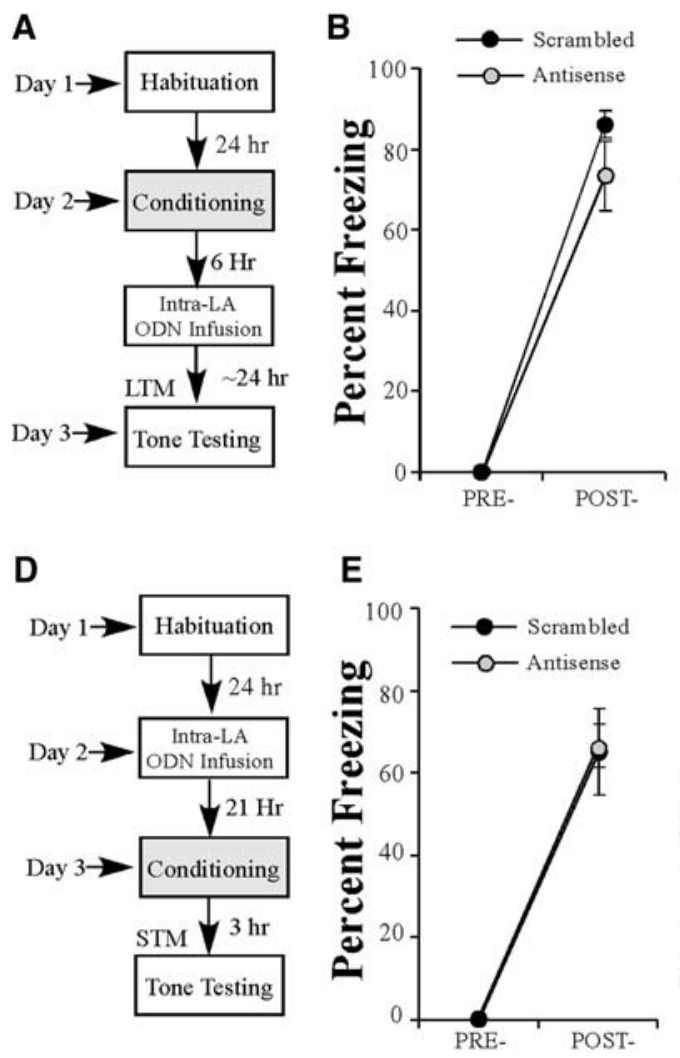

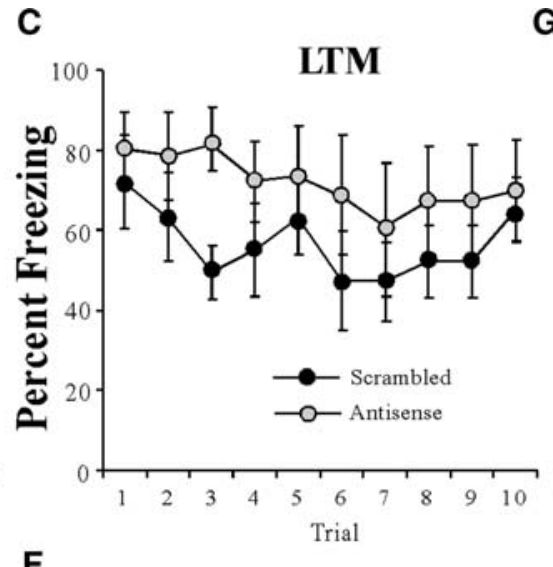

$\mathbf{F}$

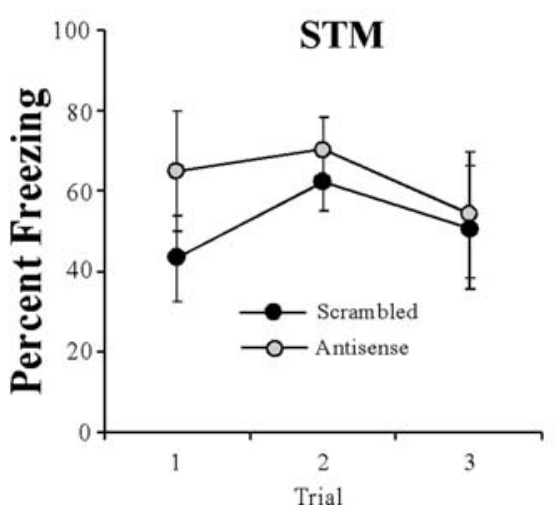

G
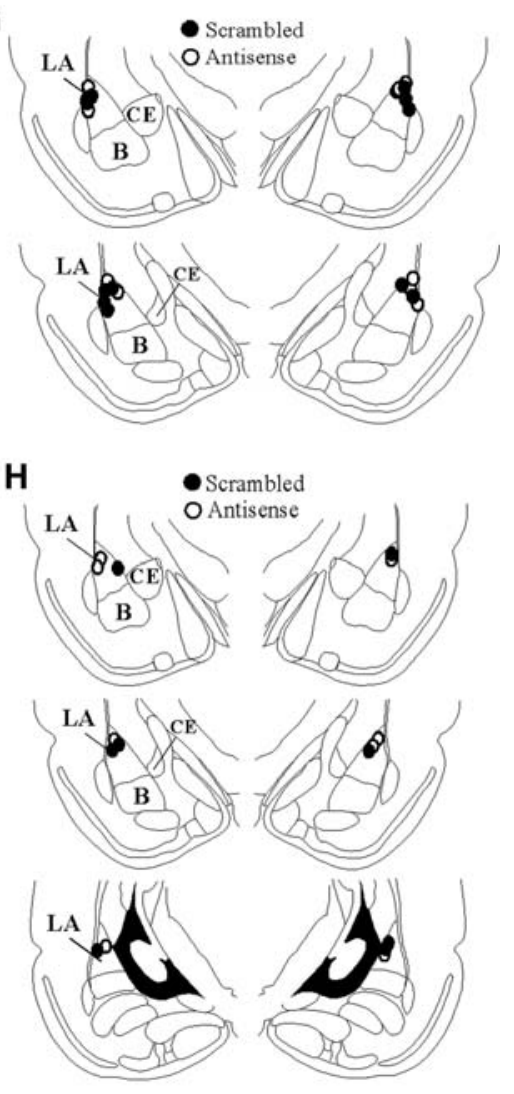

Figure 4. The effects of EGR-1 antisense infusions in the LA are temporally graded and do not result in hyperactivity $24 \mathrm{~h}$ later. ( $A$ ) Schematic of the behavioral paradigm. Rats were conditioned followed by intra-LA infusion of either antisense $(n=5)$ or scrambled $(n=6)$ ODN $(250 \mathrm{pmol} ; 1 \mu \mathrm{L} /$ side) $6 \mathrm{~h}$ later. Auditory fear memory was assessed $\sim 24 \mathrm{~h}$ after training. (B) Post-shock freezing in each group immediately after the conditioning trial. (C) Auditory fear memory of both antisense and scrambled groups across all 10 tone presentations assessed $18 \mathrm{~h}$ after infusions. (D) Schematic of the behavioral paradigm. Rats were given intra-LA infusion of either EGR-1 antisense $(n=4)$ or scrambled $(n=4)$ ODN $(250 \mathrm{pmol} ; 1 \mu \mathrm{L} / \mathrm{side}) 21 \mathrm{~h}$ before conditioning. Auditory fear memory was assessed $3 \mathrm{~h}$ later (at the same time LTM was assessed in the initial experiments). (E) Post-shock freezing in each group immediately after the conditioning trial. ( $F$ ) Auditory fear memory assessed $3 \mathrm{~h}$ after conditioning for both antisense and scrambled groups across all three tone presentations. $(G)$ Histological verification of cannula placements for rats infused with EGR-1 antisense $(O)$ and EGR-1 scrambled ODN $(\bullet) 6 \mathrm{~h}$ following conditioning $(B, C)$. $(H)$ Histological verification of cannula placements for rats infused with EGR-1 antisense $(O)$ and EGR-1 scrambled ODN $(\bullet) 24 \mathrm{~h}$ prior to conditioning $(E, F)$. Panels adapted from Paxinos and Watson (1998) and reprinted with permission from Elsevier $(1) 1998$.

during the LTM test in our initial experiments are caused by some nonspecific effect of EGR-1 antisense on general activity levels, which hinders fear memory expression. Cannula placements are shown in Figure $4 \mathrm{H}$.

\section{EGR-1 is significantly up-regulated in the LA following auditory fear memory retrieval and is required for fear memory reconsolidation}

In our first series of experiments, we asked whether auditory fear conditioning regulates EGR-1 expression in the LA, and whether training-induced regulation of EGR-1 in LA neurons is critical for memory consolidation of auditory fear conditioning. In this second series of experiments, we asked whether EGR-1 is critical for reconsolidation of an auditory fear memory in the LA. Previous studies that have examined the role of EGR-1 in contextual fear memory retrieval have produced conflicting findings; Hall et al. (2001b) showed that retrieval of a contextual fear memory induced EGR-1 mRNA expression in the LA, while Malkani and Rosen (2000) failed to find this effect (Hall et al. 2001b). In this second series of experiments, we first asked whether retrieval of an auditory fear memory regulates the expression of EGR-1 protein in the LA. We then asked whether EGR-1 expression in the
LA is obligatory for auditory fear memory reconsolidation after retrieval.

\section{EGR-1 is significantly up-regulated in the LA following auditory fear memory retrieval}

In our first series of experiments, we asked whether EGR-1 is regulated by memory retrieval as it is during initial auditory fear conditioning. To examine this question, rats underwent auditory fear conditioning followed $24 \mathrm{~h}$ later by either a tone reactivation trial ("Reactivated") or a no-reactivation trial in which they were placed in the reactivation chamber but not presented with a tone ("Non-Reactivated"). A group of naïve rats was handled but did not undergo conditioning or memory reactivation ("Naïve"). As in our previous immunolabeling experiments, rats in our experiment received extensive habituation to both handling and to the conditioning and testing chambers for $4 \mathrm{~d}$ prior to fear conditioning and memory retrieval testing. Using immunohistochemistry, we then examined EGR-1 protein expression in reactivated rats compared to non-reactivated and naïve controls.

A high level of EGR-1 labeled cells was observed in the reactivated group relative to both the naïve and non-reactivated 

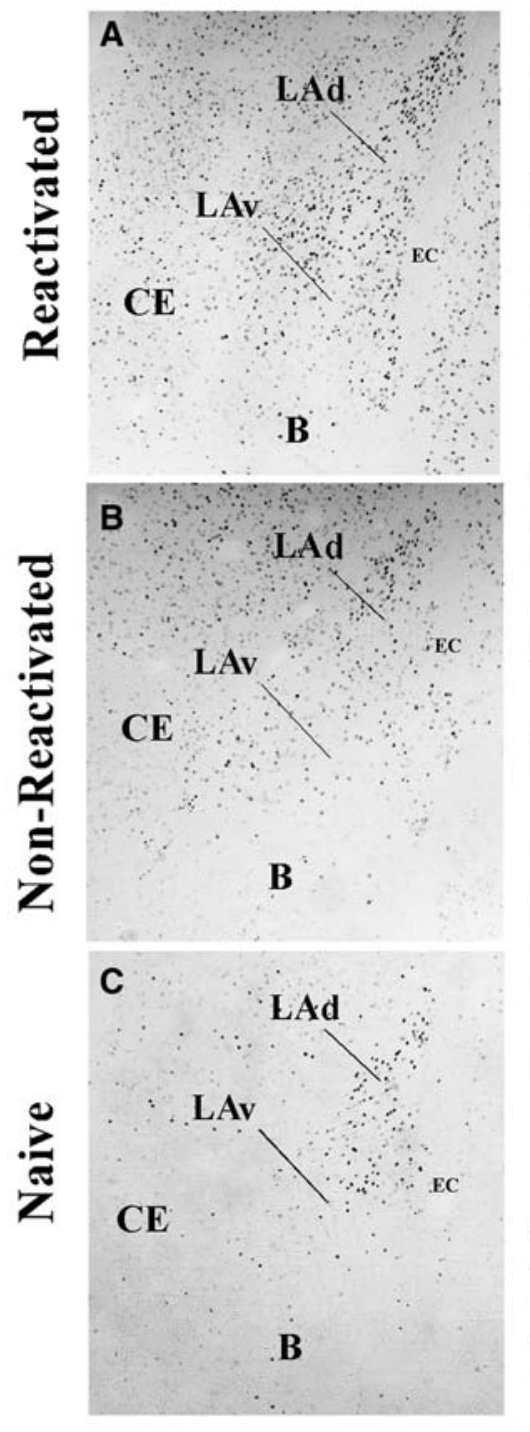

2. Auditory fear memory retrieval regulates EGR-1 protein in the $L A$. (A-C) Representative $10 X$ photomicrographs of immunolabeled EGR-1 cells in a Reactivated, Non-Reactivated and Naive rat, respectively. $(D, E)$ Higher level (20X and 40X, respectively) magnifications of EGR-1 labeled cells from the Reactivated rat. $(F)$ Quantification of EGR-1 labeled cells in the CE, B, LAv, and LAd of Naiive $(n=5)$, Non-reactivated $(n=4)$, and Reactivated $(n=5)$ groups following fear memory retrieval. $* P<0.05$ relative to naïve and non-reactivated groups.

groups (Fig. 5F). Specifically, a main effect of group was observed in the $\operatorname{LAd}\left(F_{(2,11)}=6.50, P<0.01\right)$ and the $\operatorname{LAv}\left(F_{(2,15)}=12.69\right.$, $P<0.01)$, but not the B $\left(F_{(2,11)}=2.65, P>0.05\right)$ or CE $\left(F_{(2,11)}=\right.$ $0.06, P>0.05)$. Duncan's post-hoc tests revealed significant increases in EGR-1 labeled cells in the reactivated group within the LAd and LAv $(P<0.01)$, but not B or CE $(P>0.05)$. Importantly, no significant differences were observed in EGR-1 labeled cells between naïve and non-reactivated groups in any of the amygdala subnuclei $(P>0.05)$. Representative photomicrographs for reactivated, non-reactivated, and naïve rats are displayed in Figure 5A-C, and higher magnification photomicrographs of a reactivated rat are displayed in Figure 5D,E.
Thus, retrieval of an auditory fear memory promotes significant regulation of EGR-1 in the amygdala in an anatomically restricted manner; retrievalinduced EGR-1 expression was observed in the LAd and LAv, but not the CE or B nuclei. Further, this effect is specific to those rats receiving memory reactivation; it is not observed in rats that are exposed to the testing chamber in the absence of memory reactivation.

\section{EGR-1 knockdown in the LA impairs fear memory reconsolidation}

To examine the role of EGR-1 in auditory fear memory reconsolidation, rats were trained with two tone-shock pairings, followed $24 \mathrm{~h}$ later by infusion with either EGR-1 scrambled or antisense ODNs $(250 \mathrm{pmol} ; 1 \mu \mathrm{L})$ and a tone reactivation trial $90 \mathrm{~min}$ later (Fig. 6A). There was no difference in levels of pre- vs. post-shock freezing between the scrambled and antisense groups (Fig. 6B). A two-way repeated measures ANOVA revealed only a significant main effect of trial $\left(F_{(2,16)}=89.79, P<0.01\right)$; there was no significant main effect of group $\left(F_{(1,8)}=2.52, P>0.05\right)$ or the group by trial interaction $\left(F_{(2,16)}=1.44\right.$, $P>0.05)$. Further, on the next day, both groups showed equivalent levels of freezing during the pre-CS period and the tone-CS presentation during the reactivation trial (Fig. 6C). An ANOVA (group by trial) revealed no significant effect of group $\left(F_{(1,8)}=0.235, P>0.05\right)$, or group by trial interaction $\left(F_{(1,8)}=\right.$ $0.124, P>0.05)$; however, there was a significant main effect of trial $\left(F_{(1,8)}=\right.$ 257.85, $P<0.01$ ), indicating that there was an increase in freezing to the tone CS relative to the pre-CS period in both groups. Three h following tone memory reactivation, rats were given a postreactivation STM (PR-STM) test (Fig. 6D). The ANOVA (group by trial) revealed no significant effect of group $\left(F_{(1,8)}=0.05, \quad P>0.05\right)$, trial $\left(F_{(2,16)}=\right.$ $2.12, P>0.05)$, and no group by trial interaction $\left(F_{(2,16)}=0.52, P>0.05\right)$.

On the following day, rats were given a post-reactivation LTM (PR-LTM) test, and the group infused with the EGR-1 antisense ODN exhibited impaired PR-LTM (Fig. 6E). The ANOVA (group by trial) revealed significant main effects of group $\left(F_{(1,8)}=32.47, P<\right.$ $0.01)$ and trial $\left(F_{(9,72)}=2.68, P<0.01\right)$, but no significant group by trial interaction $\left(F_{(9,72)}=0.50, P>0.05\right)$. As another measure of the reconsolidation deficit observed in the EGR-1 antisense ODN group, each rat's freezing score during the PR-LTM test was expressed as a percentage of that displayed during the PR-STM test (Fig. 6F). The EGR-1 antisense ODN group displayed significantly less retention during the PR-LTM test than the scrambled group, which exhibited sustained levels of retention $\left(t_{(8)}=19.0\right.$, $P<0.01)$. Thus, these data demonstrate that knockdown of 

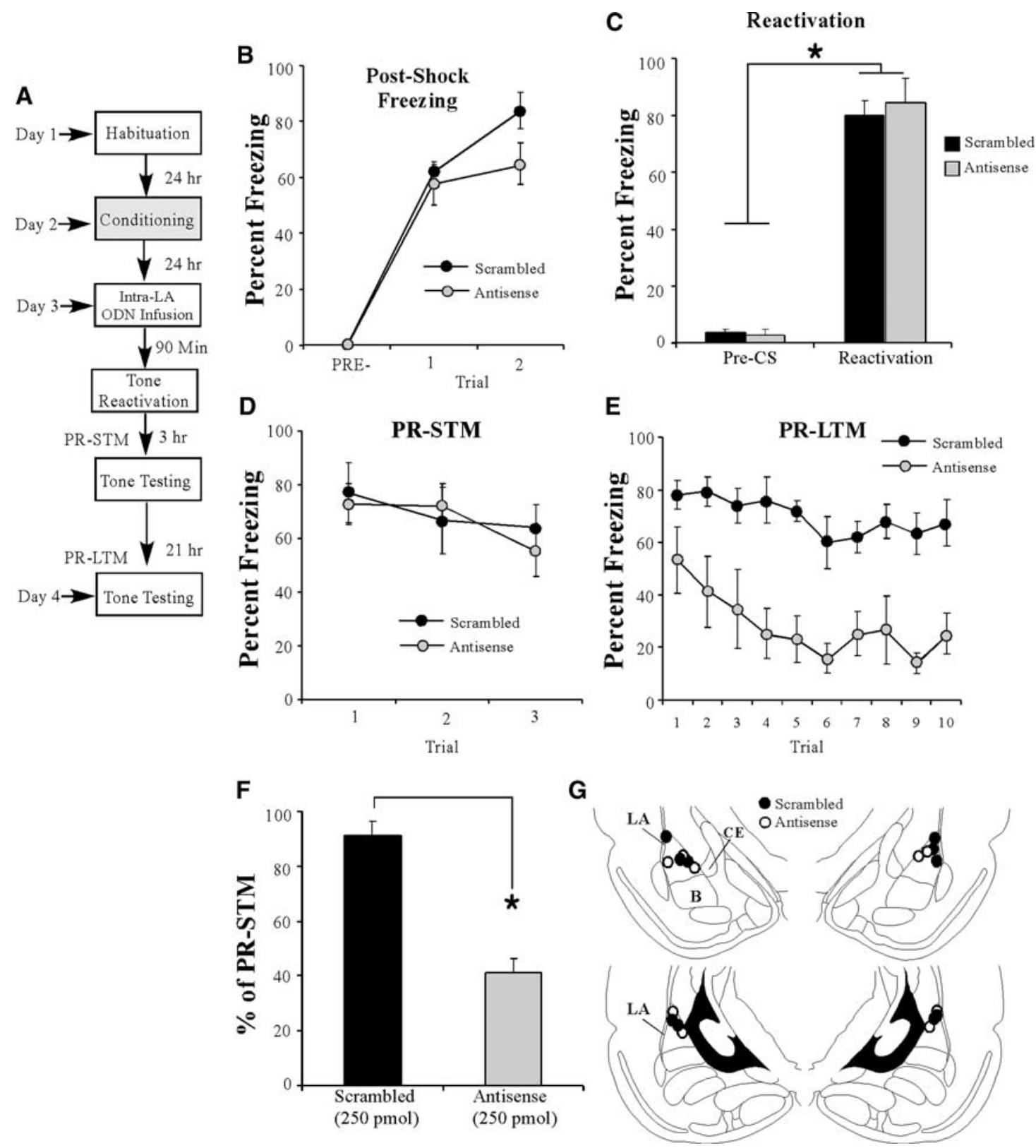

Figure 6. Antisense knockdown of EGR-1 protein in the LA impairs auditory fear memory reconsolidation. (A) Schematic of the behavioral protocol. Rats were trained followed $24 \mathrm{~h}$ later by intra-LA infusion of either ( $250 \mathrm{pmol} ; 1 \mu \mathrm{L} /$ side) EGR-1 antisense $(n=5)$ or scrambled $(n=5)$ ODN 90 min before auditory fear memory retrieval administered in a distinct context. PR-STM and PR-LTM were examined 3 and $24 \mathrm{~h}$ following the reactivation trial, respectively. (B) Post-shock freezing scores in each group immediately after the conditioning trials. (C) Memory reactivation scores in each group during the tone reactivation trial. $(D)$ Auditory fear memory assessed at $3 \mathrm{~h}$ after memory reactivation in each group across all three tone presentations. $(E)$ Auditory fear memory assessed $24 \mathrm{~h}$ after reactivation in each group across all 10 tone presentations. $(F)$ PR-LTM depicted as a percentage of PR-STM for each rat in each group. ${ }^{*} P<0.01$ relative to the scrambled group. $(G)$ Histological verification of cannula placements for rats infused with EGR-1 antisense (O) or EGR-1 scrambled ODN (•). Panels adapted from Paxinos and Watson (1998) and reprinted with permission from Elsevier ( $) 1998$.

EGR-1 in the LA interferes with PR-LTM formation, while leaving reactivation and PR-STM intact. Cannula placements are shown in Figure 6G.

\section{The effect of EGR-1 knockdown on reconsolidation of an auditory fear memory is specific to an actively reactivated memory}

To determine whether the reconsolidation deficit produced by EGR-1 knockdown prior to tone memory reactivation is specific to an actively retrieved memory, we next examined the effect of
EGR-1 knockdown on memory reconsolidation in the absence of fear memory reactivation. Trained rats were infused with either EGR-1 scrambled or EGR-1 antisense ODNs $(250$ pmol; $1 \mu \mathrm{L})$. Ninety min later, rats were placed in the testing chamber for the same amount of time as those rats that received tone reactivation in the previous experiment, but were not presented with a tone (Fig. 7A). Both groups showed similar levels of postshock freezing on the training day (Fig. 7B). A two-way repeated measures ANOVA revealed a significant main effect of trial $\left(F_{(2,18)}=144.28 P<0.01\right)$, a nonsignificant main effect of group 


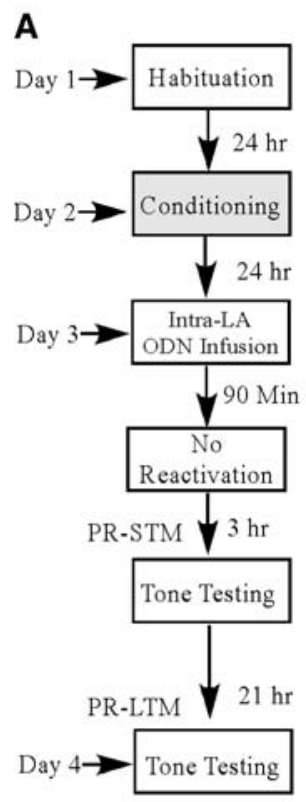

B

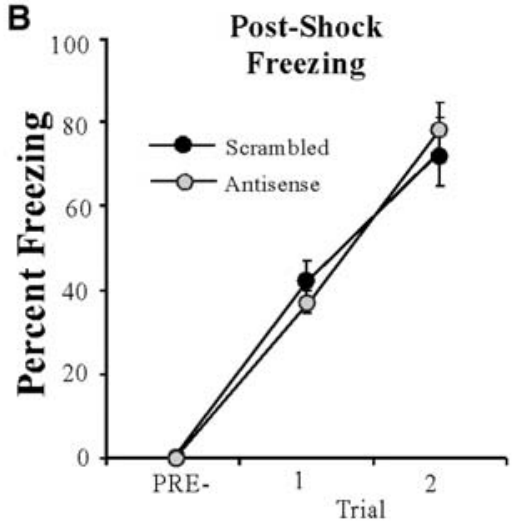

D

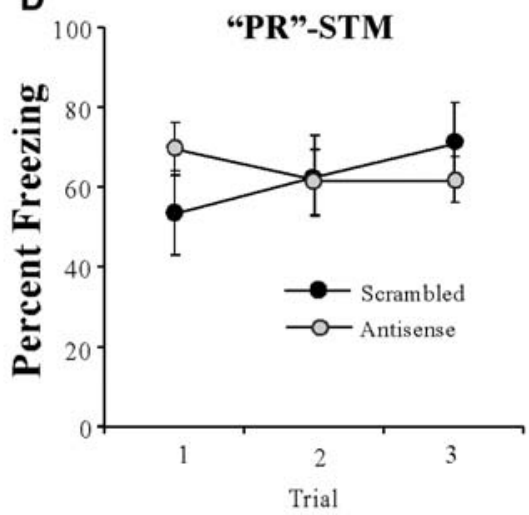

F

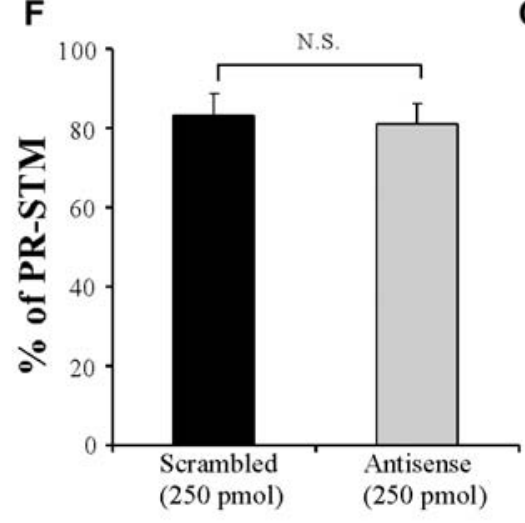

C

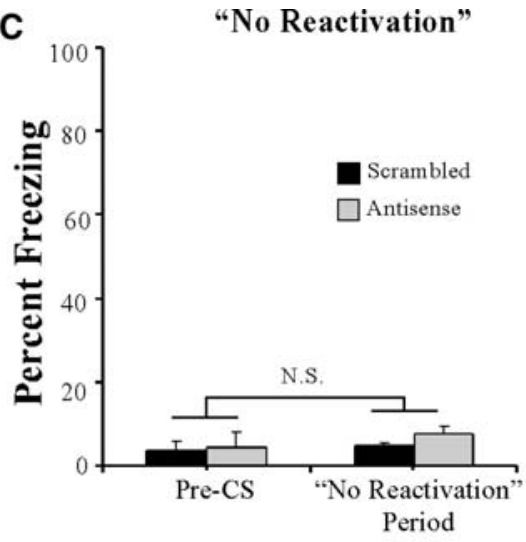

E

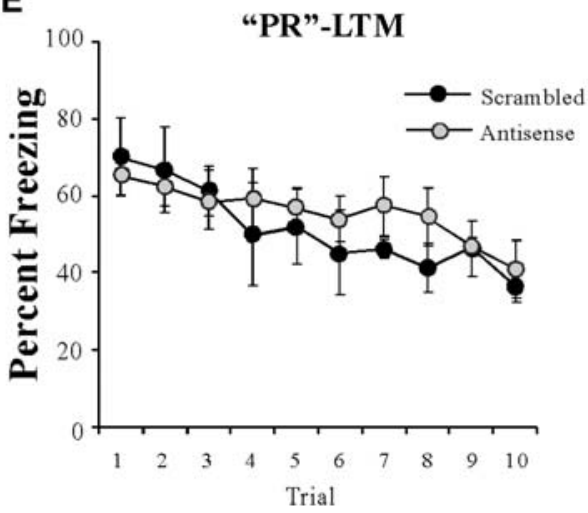

G

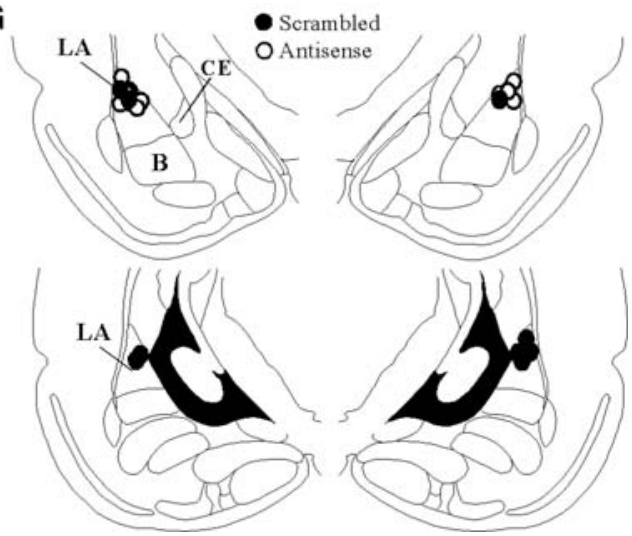

Figure 7. The effect of EGR-1 knockdown on auditory fear memory reconsolidation is specific to reactivated memories. ( $A$ ) Schematic of the behavioral protocol. Rats were trained followed $24 \mathrm{~h}$ later by intra-LA infusion of either EGR-1 antisense $(250 \mathrm{pmol} ; 1 \mu \mathrm{L} / \mathrm{side} ; n=6)$ or scrambled $(n=5)$ ODN 90 min before a "no-reactivation trial" in which rats were placed in a distinct context without tone-CS presentation. "PR"-STM and "PR"-LTM were examined 3 and 24 h following the "no-reactivation trial." (B) Post-shock freezing scores in each group immediately after the conditioning trials. (C) "Memory reactivation" scores in each group during the no-reactivation trial. $(D)$ Auditory fear memory assessed at $3 \mathrm{~h}$ after the no-reactivation trial in each group across all three tone presentations. (E) Auditory fear memory assessed $24 \mathrm{~h}$ after the no-reactivation trial in each group across all 10 tone presentations. $(F)$ "PR"-LTM depicted as a percentage of "PR"-STM for each rat in each group. ${ }^{*} P<0.01$ relative to the scrambled group. (G) Histological verification of cannula placements for rats infused with EGR-1 antisense $(O)$ or EGR-1 scrambled ODN (•). Panels adapted from Paxinos and Watson (1998) and reprinted with permission from Elsevier (C) 1998.

$\left(F_{(1,9)}=0.001, P>0.05\right)$, and a nonsignificant group by trial interaction $\left(F_{(2,18)}=0.644, P>0.05\right)$. On the next day, both groups showed equivalent levels of freezing during the "pre-CS period" and during the $30 \mathrm{sec}$ when the tone would have been presented during the reactivation trial (Fig. 7C). An ANOVA (group by trial) revealed no significant effect of group $\left(F_{(1,9)}=1.58, P>0.05\right)$, trial $\left(F_{(1,9)}=1.26, P>0.05\right)$ or group by trial interaction $\left(F_{(1,9)}=\right.$ $0.465, P>0.05)$. In addition, both groups showed equivalent
PR-STM (Fig. 7D). The ANOVA (group by trial) revealed nonsignificant effects of group $\left(F_{(1,9)}=0.03, P>0.05\right)$, trial $\left(F_{(2,18)}=0.46\right.$, $P>0.05)$, and the group by trial interaction $\left(F_{(2,18)}=2.78, P>\right.$ 0.05). Examination of freezing during the PR-LTM test also revealed no significant difference between the groups, with both groups displaying high levels of freezing (Fig. 7E). The ANOVA (group by trial) failed to reveal a significant main effect of group $\left(F_{(1,9)}=0.23, P>0.05\right)$ or group by trial interaction 
$\left(F_{(9,81)}=0.78, P>0.05\right)$; however, there was a significant main effect of trial $\left(F_{(9,81)}=5.91, P<0.01\right)$. Further, no significant difference in retention was observed between the two groups when PR-LTM was expressed as a percentage of PR-STM $\left(t_{(9)}=0.14\right.$, $P>0.05$ ) (Fig. 7F). Cannula placements can be viewed in Figure 7G. Thus, knockdown of EGR-1 in the LA does not disrupt retention of non-reactivated memories.

\section{The effect of EGR-1 knockdown in the LA on auditory fear memory reconsolidation is time-limited}

We have demonstrated that the effects of EGR-1 knockdown on initial memory consolidation are temporally graded (Fig. 4A-C). Here, we sought to determine whether the effects of EGR-1 knockdown on memory reconsolidation have similar temporal constraints. Trained rats were given a tone-reactivation trial followed $6 \mathrm{~h}$ later by intra-LA infusion of either EGR-1 scrambled or antisense ODNs $(250 \mathrm{pmol} ; 1 \mu \mathrm{L})$ followed by a PR-LTM test $18 \mathrm{~h}$ later (Fig. 8A). There was no significant difference between the scrambled and antisense groups in the level of post-shock freezing following training (Fig. 8B). A two-way repeated measures ANOVA revealed a main effect of trial $\left(F_{(2,10)}=247.49, P<0.01\right)$, but no significant main effect of group $\left(F_{(1,5)}=1.01, P>0.05\right)$ or the group by trial interaction $\left(F_{(2,10)}=0.899, P>0.05\right)$. On the next day, both groups exhibited equivalent levels of tone memory reactivation (Fig. 8C). An ANOVA (group by trial) revealed no significant effect of group $\left(F_{(1,5)}=0.137, P>0.05\right)$, or group by trial interaction $\left(F_{(1,5)}=1.04, P>0.05\right)$; however, there was a significant main effect of trial $\left(F_{(1,5)}=407.05, P<0.01\right)$, indicating that there was an increase in freezing to the tone CS relative to the pre-CS period. Furthermore, no significant group difference in freezing levels was observed during the PR-LTM test (Fig. 8D). The ANOVA revealed nonsignificant effects for group $\left(F_{(1,5)}=\right.$ $0.53, P>0.05)$, trial $\left(F_{(9,45)}=1.74, P>0.05\right)$, and the group by trial interaction $\left(F_{(9,45)}=0.86, P>0.05\right)$. Cannula placements can be viewed in Figure 8E. Thus, these findings are consistent with the time-limited role of memory reconsolidation processes (Nader et al. 2000), which likely occur within $6 \mathrm{~h}$ of memory retrieval.

\section{Discussion}

Recent work in our laboratory and others has demonstrated the importance of a number of NMDAR-driven protein kinase signaling cascades and transcription factors in the consolidation and reconsolidation of fear memories in the LA (Schafe and LeDoux
A

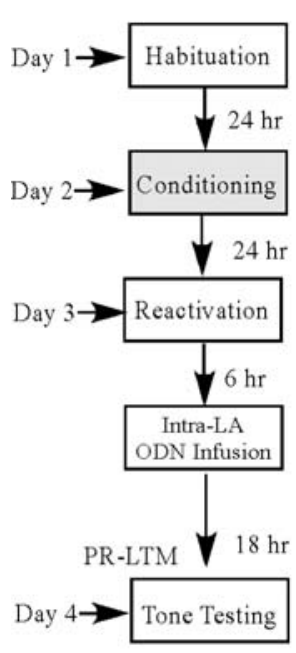

B
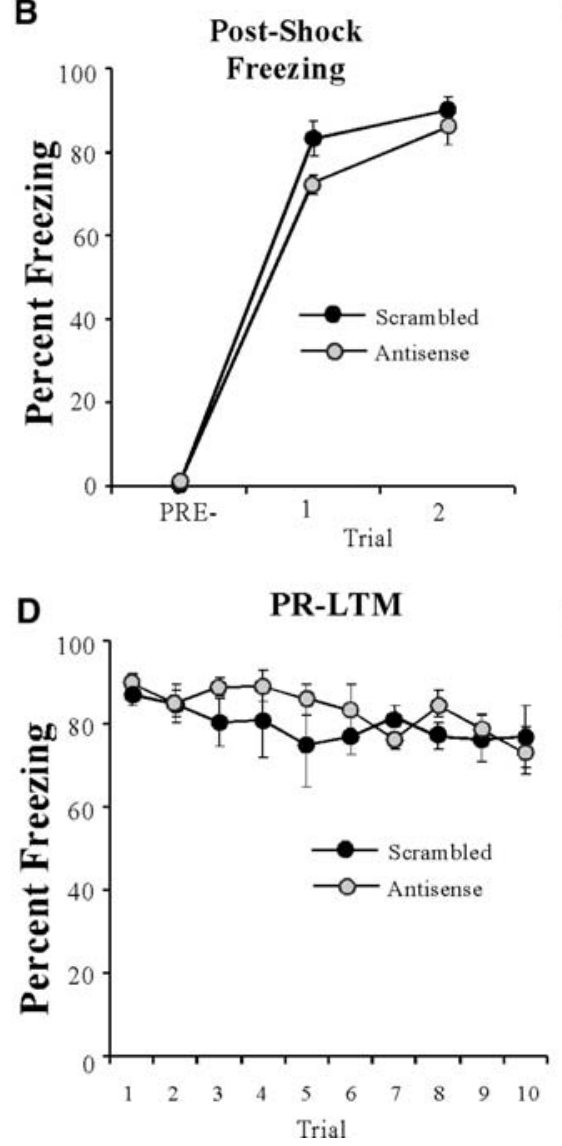

C

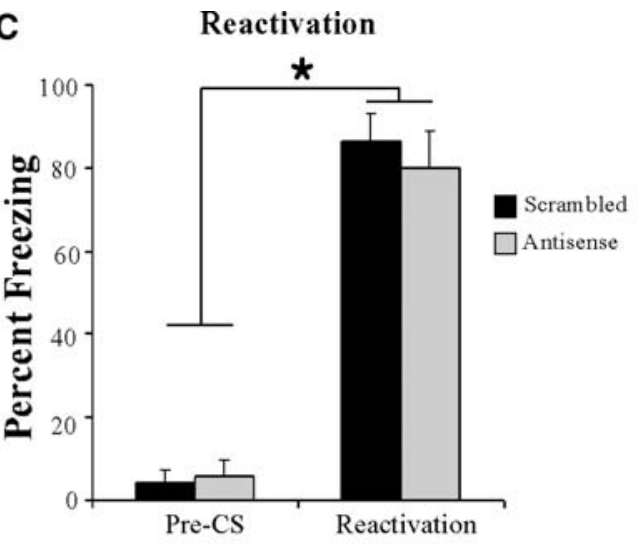

E

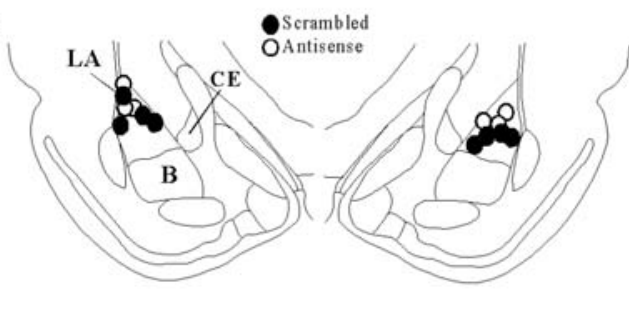

Figure 8. The effect of EGR-1 knockdown on auditory fear memory reconsolidation is temporally graded. (A) Schematic of the behavioral paradigm. Rats were trained followed $24 \mathrm{~h}$ later by a tone reactivation session in a distinct context. Rats were then given intra-LA infusion of either antisense $(n=3)$ or scrambled $(n=4)$ ODN (250 pmol; $1 \mu \mathrm{L} /$ side) $6 \mathrm{~h}$ later. Auditory fear memory was assessed $24 \mathrm{~h}$ after reactivation ( $18 \mathrm{~h}$ after infusion). (B) Post-shock freezing scores in each group immediately after the conditioning trials. (C) Memory reactivation scores in each group during the tone reactivation trial. (D) Auditory fear memory assessed $18 \mathrm{~h}$ after infusions for both antisense and scrambled groups across all 10 tone presentations. $(E)$ Histological verification of cannula placements for rats infused with EGR-1 antisense (O) or EGR-1 scrambled ODN (•). Panels adapted from Paxinos and Watson (1998) and reprinted with permission from Elsevier (C) 1998. 
2000; Schafe et al. 2000; Hall et al. 2001a; Josselyn et al. 2001; Rodrigues et al. 2001; Duvarci et al. 2005; Ben Mamou et al. 2006; Tronson et al. 2006). However, while both consolidation and reconsolidation of fear memories are known to require mRNA and protein synthesis in the LA (Bailey et al. 1999; Nader et al. 2000; Schafe and LeDoux 2000; Duvarci et al. 2008; but see Parsons et al. 2006), very little remains known about the downstream genes that are critical for fear memory consolidation and/or reconsolidation. The present study examined the role of the regulatory transcription factor EGR-1 in the consolidation and reconsolidation of auditory Pavlovian fear memories. We show that EGR-1 protein expression is significantly up-regulated in the amygdala following both auditory fear conditioning and retrieval of a recently acquired auditory fear memory. Further, we show that antisense knockdown of EGR-1 in the LA impairs both consolidation and reconsolidation of an auditory fear memory.

Previous studies that have examined the role of EGR-1 in fear memory consolidation and reconsolidation have largely focused on examining the regulation of EGR-1 mRNA in the LA following contextual fear conditioning (Hall et al. 2000; Malkani and Rosen 2000; Malkani et al. 2004) or retrieval of a contextual fear memory (Hall et al. 2001b). Little consensus, however, has emerged from these findings, with one study suggesting that fear acquisition, but not retrieval, regulates EGR-1 mRNA in the LA (Malkani and Rosen 2000), and others suggesting the opposite pattern of findings (Hall et al. 2000, 2001b). While the reasons for these discrepant findings are not entirely clear, it has been suggested that the use of contextual fear conditioning paradigms to study the role of EGR-1 in fear memory consolidation processes may be at least partially responsible (Davis et al. 2003). In a typical contextual fear conditioning task, an animal is introduced to a novel conditioning chamber and, after a variable delay, exposed to a footshock. During this experience, the animal not only learns to fear the context but also learns about the novel context itself (Fanselow 1980; Rudy et al. 2004). Interestingly, the amygdala has been shown to be a critical modulator of the formation of contextual memory representations, but only when the context is novel (Huff et al. 2005). Accordingly, any study that examines the regulation of genes in the amygdala following contextual fear learning must distinguish between gene expression related to contextual fear learning and that related to context learning and/or novelty alone (Hall et al. 2000; Ploski et al. 2010). In the present study, we attempted to circumvent these issues by examining the regulation of EGR-1 in the LA following auditory fear conditioning in rats that had been repeatedly exposed to the training context, a procedure that allowed us to examine trainingrelated changes in gene expression in the LA in the absence of those driven by exposure to a novel context (Ploski et al. 2010). Using this approach, we were able to show that both acquisition and retrieval of an auditory fear memory regulate the expression of EGR-1 protein in the LA in a manner that cannot be accounted for by exposure to a novel context, shock, or tone alone.

While EGR-1 has been widely assumed to play a selective role in long-lasting forms of synaptic plasticity and memory, surprisingly few studies have explicitly and systematically examined its role in different phases of memory formation. Jones et al. (2001) showed that mice with a targeted disruption of the zif-268 gene have impaired LTM (at $24 \mathrm{~h}$ ), but intact STM (within $10 \mathrm{~min}$ ), of olfactory discrimination in the social transmission of food preference task and in hippocampal-dependent object recognition memory (Jones et al. 2001). In our experiments, we show that antisense knockdown of EGR-1 in the LA impairs LTM at $24 \mathrm{~h}$ following fear conditioning, but leaves fear acquisition and STM intact (at $3 \mathrm{~h}$ ). The observation of intact acquisition and STM but impaired LTM in each of these studies is consistent with a role for EGR-1 in the later phases of memory consolidation (Jones et al. 2001; Davis et al. 2003), and also rules out the possibility that the observed LTM deficits following EGR-1 deletion/ knockdown may be due to altered sensory processing or other motivational or performance factors during the acquisition phase of the memory tasks. Further, in our study we show that the effects of EGR-1 knockdown on fear memory consolidation are timelimited and specific to the LA. Extra- or unilateral-LA infusions of EGR-1 antisense failed to result in impaired memory consolidation, suggesting that it is unlikely that the consolidation deficit observed following intra-LA infusion of EGR-1 antisense can be attributed to passive diffusion to structures surrounding the LA. Finally, we showed that the consolidation deficit observed following EGR-1 antisense administration cannot be attributed to slowly emerging toxicity, damage to the LA, or to hyperactivity, all of which may render the rat unable to exhibit intact freezing behavior during the LTM test. Retraining and retesting for LTM in the antisense group from the initial experiment in the absence of antisense infusions resulted in high levels of freezing equivalent to those exhibited by the scrambled group during the initial LTM test, and infusion of an EGR-1 antisense ODN $24 \mathrm{~h}$ prior to training has no effect on freezing levels in rats conditioned and tested for STM the next day. Collectively, these findings provide strong evidence that EGR-1 is critical for fear memory consolidation of auditory fear conditioning in the LA, and support and extend those of a previous study that showed that EGR-1 is critical for LTM formation of contextual fear conditioning in the amygdala (Malkani et al. 2004).

While it is well established that fear memory reconsolidation requires CREB-driven transcriptional regulation (Kida et al. 2002; Mamiya et al. 2009), few studies have examined the functional role of CREB-driven genes in fear memory reconsolidation processes within the LA. Previous studies that have examined the regulation of EGR-1 mRNA following fear memory retrieval have focused exclusively on contextual fear conditioning, and, as with those that have focused on fear acquisition, the findings have been largely inconsistent. Hall et al. (2001b) showed that retrieval of both contextual and auditory fear memories induces EGR-1 mRNA expression in the LA, while Malkani and Rosen (2000) failed to find evidence of regulation of EGR-1 mRNA in the LA following context memory retrieval (Malkani and Rosen 2000; Hall et al. 2001b). In our experiments, we showed that EGR-1 protein expression is regulated by retrieval of an auditory fear memory in the LA, but only in the group receiving memory reactivation. Further, consistent with the findings of Lee et al. (2005), our behavioral experiments show that retrieval-induced expression of EGR-1 in the LA is critical for fear memory reconsolidation; intra-LA infusion of EGR-1 antisense prior to retrieval leaves PR-STM (tested at $3 \mathrm{~h}$ ) intact, while PR-LTM (tested at $24 \mathrm{~h}$ ) is impaired. Further, this effect on fear memory reconsolidation was observed to be time-limited and specific to actively reactivated memories; EGR-1 knockdown in the absence of fear memory retrieval failed to result in a reconsolidation deficit. This pattern of findings attests to the specificity of our memory reactivation parameters; rats in the non-reactivation session demonstrate very little freezing to the testing context, suggesting that there is little to no context generalization between our training and testing contexts. This is a key demonstration that we have specifically reactivated the auditory fear memory in the absence of the contextual fear memory, which was also likely acquired during the training session. Collectively, these findings support the conclusion that EGR-1 is required for fear memory reconsolidation in the LA, and are consistent with a general role for EGR-1 in memory reconsolidation processes as previously shown in hippocampal-dependent memory (Bozon et al. 2003b; Lee et al. 2004; Lee 2008) and drug-seeking behavior (Lee et al. 2005, 2006). 
Little is known about the mechanisms by which EGR-1 contributes to long-term synaptic plasticity, memory consolidation, and reconsolidation. In cultured neurons, both glutamatergic signaling (Condorelli et al. 1994) and L-type voltage-gated calcium channels (Murphy et al. 1991) have been shown to regulate EGR-1 expression. Further, EGR-1, along with the nuclear transcription factors Elk-1 and CREB, have been shown to be regulated by ERK/MAPK signaling during long-term potentiation (LTP) in the dentate gyrus (Davis et al. 2000), suggesting that one or both of these transcription factors plays a critical role in ERK-driven EGR-1 transcription. Several downstream target genes of EGR-1 have been identified, most notably are those encoding for the presynaptic vesicle proteins synapsin I/II (Thiel et al. 1994; Petersohn et al. 1995). In the hippocampus, EGR-1 protein has been shown to increase in the dentate gyrus $2 \mathrm{~h}$ following LTP-inducing stimulation of the perforant path (Davis et al. 2000), with a corresponding increase in synapsin I mRNA within dentate granule cells at 3-5 $\mathrm{h}$ and that of synapsin I protein in mossy fiber terminals by $5 \mathrm{~h}$ (Hicks et al. 1997). This pattern of findings, which suggests that EGR-1 promotes a kind of serial, trans-synaptic plasticity within hippocampal networks, is of particular interest in light of recent findings that suggest that auditory fear conditioning may be characterized by a similar process of serial plasticity within the amygdala, both within the LA (Repa et al. 2001; Medina et al. 2002) and between the LA and adjacent amygdala nuclei (Paré et al. 2004; Wilensky et al. 2006). Further, our laboratory has recently observed that auditory fear conditioning promotes significant increases in synapsin protein in the LA (including the LAd and LAv) within $24 \mathrm{~h}$ following conditioning (Ota et al. 2010). Future studies will be required to examine whether this effect is driven by EGR-1 and how it relates at the synaptic level to both consolidation and reconsolidation processes in the amygdala.

In summary, the results of the present study provide strong evidence that EGR-1 is critical for auditory fear memory consolidation and reconsolidation processes in the LA. These findings expand nicely upon the findings of previous studies examining the role of EGR-1 in other learning paradigms, including contextual fear memory (Hall et al. 2000; Malkani and Rosen 2000; Malkani et al. 2004), and make an additional contribution toward understanding the cellular and molecular processes underlying emotional memory formation in the amygdala.

\section{Materials and Methods}

\section{Subjects}

Adult-male Sprague-Dawley rats (Harlan), weighing 300-350 g and aged 2-3 mo, were housed individually in plastic cages and maintained on a 12:12 h light/dark cycle with food and water provided ad libitum.

\section{Surgery}

Rats were anesthetized with i.p. administration of Ketamine $(100 \mathrm{mg} / \mathrm{kg})$ and Xylazine $(6.0 \mathrm{mg} / \mathrm{kg})$ and implanted with 26-gauge stainless-steel guide cannulas (Plastics One) in the LA $(-3.2 \mathrm{~mm}, \pm 5.2 \mathrm{~mm},-8.0 \mathrm{~mm}$ relative to bregma). Guide cannulas were secured to screws in the skull using a mixture of dental acrylic and cement, and 31-gauge dummy cannulas were inserted into the guide to prevent obstruction. Buprenex $(0.2 \mathrm{mg} / \mathrm{kg})$ was administered as an analgesic and rats were provided with at least $5 \mathrm{~d}$ postoperative recovery time. All surgical procedures were conducted under the guidelines provided in the National Institutes of Health Guide for the Care and Use of Experimental Rats and were approved by the Yale University Institutional Animal Care and Use Committee.

\section{Western blotting}

For Western blotting experiments, cannulated rats were handled and habituated to the training chamber for $2 \mathrm{~d}$. On the third day they were given intra-LA infusion of an EGR-1 antisense ODN ( $250 \mathrm{pmol} ; 1 \mu \mathrm{L})$ on one side of the brain, and a scrambled ODN ( $250 \mathrm{pmol} ; 1 \mu \mathrm{L})$ on the contralateral side. Ninety min later, rats were subjected to auditory fear conditioning consisting of a $30-\mathrm{sec}, 5-\mathrm{kHz}, 75-\mathrm{dB}$ tone which coterminated with a 1-sec, 2.0-mA foot shock. Two $h$ after training, rats were given an overdose of chloral hydrate $(600 \mathrm{mg} / \mathrm{kg} ;$ i.p. $)$, and brains were removed and frozen at $-80^{\circ} \mathrm{C}$ until processed. Punches containing the LA were obtained with a $1 \mathrm{~mm}$ punch tool (Fine Science Tools) from $400-\mu \mathrm{m}$-thick sections taken on a sliding freezing microtome. Punches were manually dounced in $100 \mu \mathrm{L}$ of ice-cold hypotonic lysis buffer $(10 \mathrm{mM}$ Tris- $\mathrm{HCl}, \mathrm{pH} 7.5,1 \mathrm{mM}$ EDTA, $2.5 \mathrm{mM}$ sodium pyrophosphate, $1 \mathrm{mM}$ phenylmethylsulfonyl fluoride, $1 \mathrm{mM} \beta$-glycerophosphate, $1 \%$ Igepal CA-630, $1 \%$ protease inhibitor cocktail [Sigma], and $1 \mathrm{mM}$ sodium orthovanadate). Sample buffer was immediately added to the homogenates, and the samples were boiled for $4 \mathrm{~min}$. Homogenates were electrophoresed on $10 \%$ Tris- $\mathrm{HCl}$ gels and blotted to Immobilon-P (Millipore). Western blots were then blocked in TTBS buffer (50 mM Tris- $\mathrm{HCl}, \mathrm{pH} 7.5,150 \mathrm{mM} \mathrm{NaCl}$, and $0.05 \%$ Tween-20) with 5\% dry milk and then incubated with anti-EGR-1 antibody (1:1000; Santa Cruz Biotechnology; lot B-1309; Catalog \#SC110). Blots were then incubated with anti-rabbit antibody conjugated to horseradish peroxidase (Cell Signaling) and developed using West Dura chemiluminescent substrate (Pierce Laboratories). Western blots were developed in the linear range used for densitometry. Densitometry was conducted using Image J software. To control for inconsistencies in loading, optical densities were normalized to GAPDH protein (1:5000; Abcam). Data were normalized to the average value of scrambled ODN controls, and analyzed using $t$-tests.

\section{Immunohistochemical experiments}

Two immunohistochemical experiments were conducted to examine EGR-1 expression during fear memory consolidation. In the first experiment (Fig. 1B), rats were habituated to handling for $2 \mathrm{~d}$ before training. On the third day, "Paired" rats received three conditioning trials consisting of a $30-\mathrm{sec}, 5-\mathrm{kHz}, 75-\mathrm{dB}$ tone that coterminated with a $1-\mathrm{sec}, 0.5-\mathrm{mA}$ foot shock. The intertrial interval (ITI) was, on average, $120 \mathrm{sec}$, and the total training time lasted 9 min. "Immediate Shock" control rats were placed in the conditioning chamber followed immediately by three $0.5-\mathrm{mA}$ footshocks, and were then immediately returned to their home cage. This procedure allows the experimenter to control for shockinduced changes in gene expression in the absence of a context-shock association (Fanselow 1980). "Naïve" control rats were handled and sacrificed without exposure to the conditioning chamber. In the second experiment (Fig. 1H), we compared Naïve and Paired rats to a group receiving three presentations of the tone $(30 \mathrm{sec}, 5 \mathrm{kHz}, 75 \mathrm{~dB}$ ) in the absence of footshocks ("Tone Alone") to determine whether exposure to tone alone is sufficient to promote EGR-1 expression within the LA. In this second experiment, rats were habituated to handling and to the conditioning chamber for $4 \mathrm{~d}$ ( $20 \mathrm{~min} /$ day) prior to conditioning to rule out the possibility that exposure to the conditioning chamber alone was driving EGR-1 expression in the LA (Ploski et al. 2010). Two h after training, shock, or tone exposure, rats in both experiments were rapidly and deeply anesthetized with chloral hydrate $(600 \mathrm{mg} / \mathrm{kg}$, i.p.) and transcardially perfused with PBS, followed by ice-cold $4 \%$ paraformaldehyde in $0.1 \mathrm{M}$ phosphate buffer $(\mathrm{PB})$.

For immunohistochemistry experiments examining EGR-1 expression following auditory fear memory retrieval, rats were habituated to handling and to both conditioning and testing chambers (30 min/day/chamber) prior to auditory fear conditioning consisting of two tone-shock pairings $(30 \mathrm{sec}, 5 \mathrm{kHz}$, $75 \mathrm{~dB}$; $0.5 \mathrm{~mA}$ ). The conditioning chamber was a lit chamber with a grid floor, while the testing chamber was dark and contained a black plastic floor that had been washed with a distinctive peppermint soap. Twenty-four $\mathrm{h}$ following conditioning, rats in 
the "Reactivation" group were placed in the testing chamber and presented with a single tone CS (30 sec, $5 \mathrm{kHz}, 75 \mathrm{~dB})$. Rats in the "No Reactivation" group were placed in the testing chamber for the same amount of time as those in the "Reactivation" group, but were not presented with a tone reactivation trial. All rats were overdosed with chloral hydrate and transcardially perfused $2 \mathrm{~h}$ following the reactivation (or "no reactivation") session. "Naïve" rats were handled but not exposed to either the conditioning or testing chambers prior to sacrifice.

Brains were removed and post-fixed in $4 \%$ paraformaldehyde-PB for $12 \mathrm{~h}$ and then cryoprotected in $20 \%$ glycerol- $0.1 \mathrm{M}$ $\mathrm{PB}$ for $48-72 \mathrm{~h}$. Free-floating sections $(40 \mu \mathrm{m})$ containing the LA were cut using a sliding microtome and collected in phosphate-buffered saline (PBS) containing $0.1 \%$ sodium azide for storage. Every sixth section was processed for EGR-1 immunoreactivity. After extensive washing, sections were blocked in TBS consisting of $1 \%$ bovine serum albumin (BSA; Sigma Fraction V, Catalog \#A-3059)-0.1\% Triton X-100. Slices were then incubated overnight at room temperature in anti-EGR-1 antibody (1:10,000, Cell Signaling, rabbit polyclonal, Catalog \#4153; or 1:2,000, Santa Cruz Biotechnology, rabbit polycolonal, Catalog \#SC110) in TBS-1\% BSA-0.1\% Triton X-100. Following three washes in TBS, tissue sections were visualized using VectaStain $\mathrm{ABC}$ kit (Vector Laboratories) and developed in DAB peroxidase substrate (Sigma) for $5 \mathrm{~min}$. Sections were mounted on Fisherbrand electrostatic slides and coverslipped.

Sections from comparable anterior-posterior levels were selected for scoring, approximately $3.2-3.4 \mathrm{~mm}$ posterior to Bregma. At this level, the LA, CE, and basal nuclei are all well represented (see Fig. 1A). Cell counts were taken from at least five sections per rat and scored using Image J. For analysis, cell counts for each region were averaged into a single score for each rat, and data were analyzed using ANOVA.

\section{Oligodeoxynucleotide design and preparation}

EGR-1 antisense and scrambled oligodeoxynucleotide (ODN; Midland Certified Reagent Company) design followed the guidelines used in a previous study (Malkani et al. 2004). The EGR-1 ODN encoded an antisense sequence for the EGR-1 mRNA sequence near the translation start site (GenBank accession number NM 012551, bases 348-365). The scrambled ODN served as a control and did not show significant homology to sequences in the GenBank database. Both ODNs contained phosphorothioate linkages on the bases of both the $5^{\prime}$ and $3^{\prime}$ ends and phosphodiester internal bonds, as this nucleotide design is reportedly more stable than unmodified phosphodiester ODNs in vivo and less toxic than fully phosphorothioate ODNs (Guzowski et al. 2000; Guzowski 2002). The following sequences were used (" " denotes a phosphorothioate linkage): 5'- G $\sim$ GTAGTTGTCCATGGTG $\sim$ G-3' (antisense) and 5' - G TTGGAGTCGGTGGTTC A-3' (scrambled). This antisense sequence has previously been shown to effectively knockdown EGR-1 protein expression in the amygdala (Malkani et al. 2004).

\section{Verification of ODN diffusion}

To determine the extent of EGR-1 ODN diffusion, rats were infused with a biotinylated EGR-1 antisense ODN (Midland Certified Reagent Company). The biotin-EGR-1-ODN was infused bilaterally at the same rate, volume, and concentration used in the behavioral experiments ( $250 \mathrm{pmol} ; 1 \mu \mathrm{L}$; see below). Rats were perfused 30,60 , and $180 \mathrm{~min}$ later using the same procedures described above. Forty $\mu \mathrm{m}$ slices containing the LA were taken from the brains on a sliding microtome and every sixth section was processed using a standard $\mathrm{ABC}-\mathrm{DAB}$ reaction to determine the extent of the diffusion and cellular uptake of the ODN.

\section{Behavioral procedures}

Rats were handled for $2 \mathrm{~d}$ prior to conditioning. On the second handling day, dummy cannulas were removed and infusion cannulas were briefly inserted. Rats were then habituated to the conditioning chamber for 10 min (Day 1). The following day (Day 2), rats in the "consolidation" experiment received intraLA infusion of either EGR-1 antisense or scrambled ODN ( $250 \mathrm{pmol} ; 1 \mu \mathrm{L} / \mathrm{side}$ ). Infusions were made over $4 \mathrm{~min}$ and the infusion cannulas were left in place for at least $2 \mathrm{~min}$ following infusion to facilitate diffusion of the ODN throughout the LA. Ninety min following infusion, rats were placed in the conditioning chamber and received a single tone-shock pairing, consisting of a $30-\mathrm{sec}, 5-\mathrm{kHz}, 75-\mathrm{dB}$ tone that coterminated with a 1-sec, 2.0-mA foot shock. Three h after conditioning, rats were tested for short-term memory (STM) consisting of the presentation of three tones (30 sec, $5 \mathrm{kHz}, 75 \mathrm{~dB}$ ) in a distinct context consisting of a dark chamber with a black plastic floor, which was washed immediately before testing with a distinctive peppermint soap (Schafe et al. 1999). Twenty-four h later (Day 3), all rats received a long-term memory (LTM) test, which consisted of 10 tone presentations (30 sec, $5 \mathrm{kHz}, 75 \mathrm{~dB}$ ) in the same chamber in which the STM test was conducted.

For the "reconsolidation" experiment rats were habituated as before. On Day 2, rats received two tone-shock pairings consisting of a $30-\mathrm{sec}, 5-\mathrm{kHz}, 75-\mathrm{dB}$ tone, which coterminated with a 1-sec, 2.0-mA foot shock. On the following day (Day 3), rats received intra-LA infusion of antisense or scrambled ODN (250 pmol; $1 \mu \mathrm{L} /$ side). Ninety min later, rats were placed in the testing chamber and either presented with a tone CS to serve as a memory "reactivation trial," or given no tone CS presentation to serve as a "no-reactivation control." Three $\mathrm{h}$ following the reactivation trial, rats received a post-reactivation STM (PR-STM) test consisting of three tone presentations in the testing chamber. Twenty-four h later (Day 4), all rats received a post-reactivation LTM (PR-LTM) test consisting of 10 tone presentations $(30 \mathrm{sec}$, $5 \mathrm{kHz}, 75 \mathrm{~dB}$ ) in the same chamber in which the PR-STM test was conducted.

All behavioral testing was videotaped for subsequent scoring. Freezing was defined as a lack of movement, excluding that necessary for respiration, and was quantified as a percentage of the amount of time the rat spent engaged in freezing behavior during the CS presentations. All data were analyzed with analysis of variance (ANOVA) and Duncan's post-hoc t-tests. Repeated measures ANOVAs were used for multiple trial comparisons. Differences were considered significant if $P<0.05$. Unless otherwise noted only data from those rats with bilateral LA placed cannulas were included in the subsequent analyses.

\section{Acknowledgments}

This research was supported by National Institutes of Health Grant No. MH 073949 (G.E.S.) and by Yale University. This research was made with government support under and awarded by DoD, Air Force Office of Scientific Research, National Defense Science and Engineering Graduate (NDSEG) Fellowship, 32 CRF 168a (S.A.M.). We thank Dr. Kristie T. Ota for help with Western blotting experiments.

\section{References}

Abraham WC, Mason SE, Demmer J, Williams JM, Richardson CL, Tate WP, Lawlor PA, Dragunow M. 1993. Correlations between immediate early gene induction and the persistence of long-term potentiation. Neuroscience 56: 717-727.

Bailey DJ, Kim JJ, Sun W, Thompson RF, Helmstetter FJ. 1999. Acquisition of fear conditioning in rats requires the synthesis of mRNA in the amygdala. Behav Neurosci 113: 276-282.

Ben Mamou C, Gamache K, Nader K. 2006. NMDA receptors are critical for unleashing consolidated auditory fear memories. Nat Neurosci 9: 1237-1239.

Bozon B, Kelly A, Josselyn SA, Silva AJ, Davis S, Laroche S. 2003a. MAPK, CREB and zif 268 are all required for the consolidation of recognition memory. Philos Trans R Soc Lond B Biol Sci 358: 805-814.

Bozon B, Davis S, Laroche S. 2003b. A requirement for the immediate early gene zif268 in reconsolidation of recognition memory after retrieval. Neuron 40: $695-701$.

Bramham CR, Southard T, Sarvey JM, Herkenham M, Brady LS. 1996. Unilateral LTP triggers bilateral increases in hippocampal neurotrophin 
and trk receptor mRNA expression in behaving rats: Evidence for interhemispheric communication. J Comp Neurol 368: 371-382.

Cole AJ, Saffen DW, Baraban JM, Worley PF. 1989. Rapid increase of an immediate early gene messenger RNA in hippocampal neurons by synaptic NMDA receptor activation. Nature 340: $474-476$.

Condorelli DF, Dell'Albani P, Amico C, Lukasiuk K, Kaczmarek L, Giuffrida-Stella AM. 1994. Glutamate receptor-driven activation of transcription factors in primary neuronal cultures. Neurochem Res 19: 489-499.

Davis HP, Squire LR. 1984. Protein synthesis and memory: A review. Psychol Bull 96: 518-559.

Davis S, Vanhoutte P, Pages C, Caboche J, Laroche S. 2000. The MAPK/ERK cascade targets both Elk-1 and cAMP response element-binding protein to control long-term potentiation-dependent gene expression in the dentate gyrus in vivo. I Neurosci 20: $4563-4572$.

Davis S, Bozon B, Laroche S. 2003. How necessary is the activation of the immediate early gene zif268 in synaptic plasticity and learning? Behav Brain Res 142: $17-30$.

Duvarci S, Nader K, LeDoux JE. 2005. Activation of extracellular signal-regulated kinase-mitogen-activated protein kinase cascade in the amygdala is required for memory reconsolidation of auditory fear conditioning. Eur J Neurosci 21: 283-289.

Duvarci S, Nader K, LeDoux JE. 2008. De novo mRNA synthesis is required for both consolidation and reconsolidation of fear memories in the amygdala. Learn Mem 15: 747-755.

Fanselow MS. 1980. Conditioned and unconditional components of post-shock freezing. Pavlov J Biol Sci 15: 177-182.

Guzowski JF. 2002. Insights into immediate-early gene function in hippocampal memory consolidation using antisense oligonucleotide and fluorescent imaging approaches. Hippocampus 12: 86-104.

Guzowski JF, Lyford GL, Stevenson GD, Houston FP, McGaugh JL, Worley PF, Barnes CA. 2000. Inhibition of activity-dependent arc protein expression in the rat hippocampus impairs the maintenance of long-term potentiation and the consolidation of long-term memory. $J$ Neurosci 20: $3993-4001$.

Hall J, Thomas KL, Everitt BJ. 2000. Rapid and selective induction of BDNF expression in the hippocampus during contextual learning. Nat Neurosci 3: 533-535.

Hall J, Thomas KL, Everitt BJ. 2001a. Fear memory retrieval induces CREB phosphorylation and Fos expression within the amygdala. Eur J Neurosci 13: 1453-1458.

Hall J, Thomas KL, Everitt BJ. 2001b. Cellular imaging of zif268 expression in the hippocampus and amygdala during contextual and cued fear memory retrieval: Selective activation of hippocampal CA1 neurons during the recall of contextual memories. J Neurosci 21: $2186-2193$.

Håvik B, Røkke H, Bårdsen K, Davanger S, Bramham CR. 2003. Bursts of high-frequency stimulation trigger rapid delivery of pre-existing $\alpha$-CaMKII mRNA to synapses: A mechanism in dendritic protein synthesis during long-term potentiation in adult awake rats. Eur J Neurosci 17: 2679-2689.

Hicks A, Davis S, Rodger J, Helme-Guizon A, Laroche S, Mallet J. 1997. Synapsin I and syntaxin 1B: Key elements in the control of neurotransmitter release are regulated by neuronal activation and long-term potentiation in vivo. Neuroscience 79: 329-340.

Huff NC, Wright-Hardesty KJ, Higgins EA, Matus-Amat P, Rudy JW. 2005 Context pre-exposure obscures amygdala modulation of contextual-fear conditioning. Learn Mem 12: 456-460.

Jones MW, Errington ML, French PJ, Fine A, Bliss TV, Garel S, Charnay P, Bozon B, Laroche S, Davis S. 2001. A requirement for the immediate early gene Zif268 in the expression of late LTP and long-term memories Nat Neurosci 4: 289-296.

Josselyn SA, Shi C, Carlezon WA Jr, Neve RL, Nestler EJ, Davis M. 2001. Long-term memory is facilitated by cAMP response elementbinding protein overexpression in the amygdala. J Neurosci 21: 2404-2412.

Kida S, Josselyn SA, Peña de Ortiz S, Kogan JH, Chevere I, Masushige S, Silva AJ. 2002. CREB required for the stability of new and reactivated fear memories. Nat Neurosci 5: 348-355.

Knapska E, Kaczmarek L. 2004. A gene for neuronal plasticity in the mammalian brain: Zif268/Egr-1/NGFI-A/Krox-24/TIS8/ZENK? Prog Neurobiol 74: $183-211$

Lee JL. 2008. Memory reconsolidation mediates the strengthening of memories by additional learning. Nat Neurosci 11: $1264-1266$

Lee JL, Everitt BJ, Thomas KL. 2004. Independent cellular processes for hippocampal memory consolidation and reconsolidation. Science 304: 839-843.

Lee JL, Di Ciano P, Thomas KL, Everitt BJ. 2005. Disrupting reconsolidation of drug memories reduces cocaine-seeking behavior. Neuron 47: $795-801$.
Lee JL, Milton AL, Everitt BJ. 2006. Cue-induced cocaine seeking and relapse are reduced by disruption of drug memory reconsolidation. $J$ Neurosci 26: $5881-5887$.

Malkani S, Rosen JB. 2000. Specific induction of early growth response gene 1 in the lateral nucleus of the amygdala following contextual fear conditioning in rats. Neuroscience 97: 693-702.

Malkani S, Wallace KJ, Donley MP, Rosen JB. 2004. An egr-1 (zif268) antisense oligodeoxynucleotide infused into the amygdala disrupts fear conditioning. Learn Mem 11: 617-624.

Mamiya N, Fukushima H, Suzuki A, Matsuyama Z, Homma S, Frankland PW, Kida S. 2009. Brain region-specific gene expression activation required for reconsolidation and extinction of contextual fear memory. J Neurosci 29: 402-413.

Medina JF, Repa JC, Mauk MD, LeDoux JE. 2002. Parallels between cerebellum- and amygdala-dependent conditioning. Nat Rev Neurosci 3: $122-131$.

Mello CV, Clayton DF. 1994. Song-induced ZENK gene expression in auditory pathways of songbird brain and its relation to the song control system. J Neurosci 14: 6652-6666.

Moita MA, Lamprecht R, Nader K, LeDoux JE. 2002. A-kinase anchoring proteins in amygdala are involved in auditory fear memory. Nat Neurosci 5: $837-838$.

Mokin M, Keifer J. 2005. Expression of the immediate-early gene-encoded protein Egr-1 (zif268) during in vitro classical conditioning. Learn Mem 12: $144-149$.

Murphy MG, Moak CM, Byczko Z, MacDonald WF. 1991. Adenosine-dependent regulation of cyclic AMP accumulation in primary cultures of rat astrocytes and neurons. J Neurosci Res 30: 631-640.

Nader K, Schafe GE, Le Doux JE. 2000. Fear memories require protein synthesis in the amygdala for reconsolidation after retrieval. Nature 406: $722-726$.

Ota KT, Monsey MS, Wu MS, Schafe GE. 2010. Synaptic plasticity and NO-cGMP-PKG signaling regulate pre- and postsynaptic alterations at rat lateral amygdala synapses following fear conditioning. PLoS One 5: e11236. doi: 10.1371/journal.pone.0011236.

Paré D, Quirk GJ, Ledoux JE. 2004. New vistas on amygdala networks in conditioned fear. J Neurophysiol 92: 1-9.

Parsons RG, Gafford GM, Baruch DE, Redner BA, Helmstetter FJ. 2006. Long-term stability of fear memory depends on the synthesis of protein but not mRNA in the amygdala. Eur J Neurosci 23: 1853-1859.

Paxinos G, Watson C. 1998. The rat brain in stereotaxic coordinates. Academic, San Diego, CA.

Petersohn D, Schoch S, Brinkmann DR, Thiel G. 1995. The human synapsin II gene promoter. Possible role for the transcription factor zif268/egr-1, polyoma enhancer activator 3, and AP2. J Biol Chem 270: 24361-24369.

Ploski JE, Park KW, Ping J, Monsey MS, Schafe GE. 2010. Identification of plasticity-associated genes regulated by Pavlovian fear conditioning in the lateral amygdala. J Neurochem 112: 636-650.

Renaudineau S, Poucet B, Laroche S, Davis S, Save E. 2009. Impaired long-term stability of CA1 place cell representation in mice lacking the transcription factor zif268/egr1. Proc Natl Acad Sci 106: $11771-11775$.

Repa JC, Muller J, Apergis J, Desrochers TM, Zhou Y, LeDoux JE. 2001. Two different lateral amygdala cell populations contribute to the initiation and storage of memory. Nat Neurosci 4: 724-731.

Richardson CL, Tate WP, Mason SE, Lawlor PA, Dragunow M Abraham WC. 1992. Correlation between the induction of an immediate early gene, zif/268, and long-term potentiation in the dentate gyrus. Brain Res 580: 147-154.

Rodrigues SM, Schafe GE, LeDoux JE. 2001. Intra-amygdala blockade of the NR2B subunit of the NMDA receptor disrupts the acquisition but not the expression of fear conditioning. J Neurosci 21: 6889-6896.

Rodrigues SM, Schafe GE, LeDoux JE. 2004. Molecular mechanisms underlying emotional learning and memory in the lateral amygdala. Neuron 44: 75-91.

Rudy JW, Huff NC, Matus-Amat P. 2004. Understanding contextual fear conditioning: Insights from a two-process model. Neurosci Biobehav Rev 28: $675-685$.

Schafe GE, LeDoux JE. 2000. Memory consolidation of auditory pavlovian fear conditioning requires protein synthesis and protein kinase $A$ in the amygdala. J Neurosci 20: pRC96. url: http://www.jneurosci.org/cgi/ reprint/20/18/RC96.

Schafe GE, Nadel NV, Sullivan GM, Harris A, LeDoux JE. 1999. Memory consolidation for contextual and auditory fear conditioning is dependent on protein synthesis, PKA, and MAP kinase. Learn Mem 6: 97-110.

Schafe GE, Atkins CM, Swank MW, Bauer EP, Sweatt JD, LeDoux JE. 2000. Activation of ERK/MAP kinase in the amygdala is required for memory 
consolidation of Pavlovian fear conditioning. J Neurosci 20: 8177-8187.

Schafe GE, Nader K, Blair HT, LeDoux JE. 2001. Memory consolidation of Pavlovian fear conditioning: A cellular and molecular perspective. Trends Neurosci 24: 540-546.

Soulé J, Penke Z, Kanhema T, Alme MN, Laroche S, Bramham CR. 2008. Object-place recognition learning triggers rapid induction of plasticity-related immediate early genes and synaptic proteins in the rat dentate gyrus. Neural Plast 2008: 269097. doi: 10.1155/2008/ 269097.

Thiel G, Schoch S, Petersohn D. 1994. Regulation of synapsin I gene expression by the zinc finger transcription factor zif268/egr-1. J Biol Chem 269: 15294-15301.
Tronson NC, Taylor JR. 2007. Molecular mechanisms of memory reconsolidation. Nat Rev Neurosci 8: 262-275.

Tronson NC, Wiseman SL, Olausson P, Taylor JR. 2006.

Bidirectional behavioral plasticity of memory reconsolidation depends on amygdalar protein kinase A. Nat Neurosci 9: $167-169$.

Wilensky AE, Schafe GE, Kristensen MP, LeDoux JE. 2006. Rethinking the fear circuit: The central nucleus of the amygdala is required for the acquisition, consolidation, and expression of Pavlovian fear conditioning. J Neurosci 26: 12387-12396.

Received August 11, 2010; accepted in revised form October 13, 2010. 


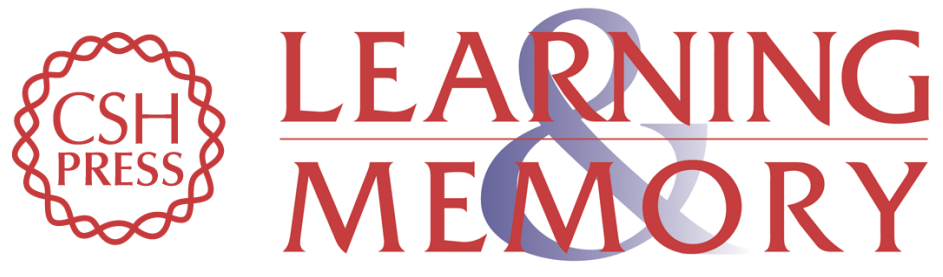

\section{Early growth response gene 1 (Egr-1) is required for new and reactivated fear memories in the lateral amygdala}

Stephanie A. Maddox, Melissa S. Monsey and Glenn E. Schafe

Learn. Mem. 2011, 18:

Access the most recent version at doi:10.1101/lm.1980211

References This article cites 58 articles, 20 of which can be accessed free at: http://learnmem.cshlp.org/content/18/1/24.full.htmI\#ref-list-1

License

Email Alerting Receive free email alerts when new articles cite this article - sign up in the box at the Service top right corner of the article or click here. 